\title{
Estudio de las dificultades de aprendizaje del hablante rumano de español como lengua extranjera
}

Study of the learning difficulties of the Romanian speaker of Spanish as a foreign language

\section{María Nayra Rodríguez-Rodríguez}

Universidad de Las Palmas de Gran Canaria España

\section{Ana María Györfi \\ Universidad de Las Palmas de Gran Canaria España}

\section{(c) $\bigodot_{\mathrm{BY}} \bigodot_{\mathrm{ND}}$}

María Nayra Rodríguez-Rodríguez: Departamento de Filología Española, Clásica y Árabe, Facultad de Filología, Universidad de Las Palmas de Gran Canaria, España. | Correo electrónico: nayra.rodriguez@ulpgc.es Ana María Györfi: Departamento de Filología Española, Clásica y Árabe, Facultad de Filología, Universidad de Las Palmas de Gran Canaria, España 


\section{Resumen}

Los objetivos principales de este estudio tratan de analizar y de profundizar en las dificultades de aprendizaje del español en la comunidad rumana residente en las Islas Canarias. Para ello, hemos pasado una serie de encuestas a través de Internet a los rumanos residentes en Canarias registrados en la Asociación RUMACAN ${ }^{1}$. Unido a los resultados de las encuestas, hemos utilizado para la investigación distintas fuentes escritas, como revistas científicas, publicaciones, textos virtuales, nacionales e internacionales, recogidas en repositorios virtuales. Nuestros resultados confirman que las dificultades que los aprendices rumanos presentan en el español hablado pueden ser extrapoladas al nivel escrito. Hemos podido comprobar que se trata de dificultades en la concordancia entre el artículo y el adjetivo con el sustantivo, la concordancia entre sujeto y verbo, el uso del verbo haber en distintos tiempos verbales, el uso del subjuntivo en oraciones subordinadas sustantiva y adjetiva, la pasiva refleja y el uso del dígrafo rr. Este estudio puede considerarse como punto de partida de futuras investigaciones relacionadas con la enseñanza del español, no solamente para el colectivo rumano, sino que para todos aquellos colectivos cuya lengua de proveniencia sea una lengua romance.

Palabras clave: rumano; Canarias; dificultades de aprendizaje; español; lengua extranjera.

\section{Abstract}

The main goals of this paper try to analyze and deepen in the difficulties of learning Spanish in the Romanian community resident in the Canary Islands. For this purpose, we have passed a series of surveys over the Internet to Romanian residents registered in the Canary

1 RUMACAN: Asociación de rumanos en Canarias. El nº de inscripción es G1/51/15764-09GC y el de identificación fiscal, G76032630. Esta asociación se constituyó el 5 de junio de 2009, al amparo del artículo 22 de la Constitución española y de las leyes orgánicas 1/2002 y ley 4/2003 de Asociaciones de Canarias. Es una asociación con capacidad jurídica y plena capacidad de obrar, careciendo de ánimo de lucro. Los principales objetivos son: a) integrar a las personas rumanas en Canarias, b) facilitar y promover la enseñanza de idiomas y c) asesorar y promover a los miembros sobre sus derechos y oportunidades a nivel laboral, público, cultural y social. 
RUMACAN² Association. Stated to the survey results, we have researched in various written sources, such as scientific journals, publications, virtual, national and international texts, collected in virtual repositories. Our results confirm that the difficulties Romanian trainees presented in spoken Spanish can be extrapolated to the written level.We have found that there are difficulties in the concordance between the article and the adjective with the noun, the agreement between subject and verb, the use of the verb haber in different tenses, use of the subjunctive in substantive subordinate clauses and adjective, the reflexive passive and use the digraph rr. This study can be considered as a starting point for future research related to the teaching of Spanish, not only to the Romanian group, but to all those groups whose language of origin is a Romance language.

Keywords: Romanian; Canarias; learning difficulties; Spanish; foreign language.

2 RUMACAN: Association of Romanians in the Canary Islands. The registration number is $\mathrm{G} / / 51 / 15764^{-}$ 09GC and tax identification is G76032630. This association was constituted on June 5, 2009, under the protection of Article 22 of the Spanish Constitution and of the organic laws 1/2002 and law $4 / 2003$ of associations of the Canary Island. It is association with legal capacity and full capacity to act non-profit. The main objetives are: a) to integrate the Romanian people in the Canary Islands, b) to facilitate and promote language teaching and c) advise and promote the members about their rights and oppotunities at the labor public, cultural and social level. 


\section{Introducción}

Actualmente, España es uno de los países de la Unión Europea con mayor tasa de inmigración. Según el INE, a fecha de 1 de enero de 2016, esta tasa supera los cuatro millones y medio. Entre las comunidades de extranjeros presentes en nuestro país, la más representativa es la comunidad rumana, con un porcentaje de 15,8 \% del total. En Canarias, hay 8.503 residentes rumanos registrados en el padrón continuo. Una de las razones por las que los rumanos eligen España es la familiaridad lingüística con el español, considerados ambos como lenguas romances. Desde el punto de vista pragmático, se considera que la inserción lingüística es el primer paso para la total integración de los inmigrantes, sea escolar, social o laboral. Desde este estudio, queremos analizar y profundizar en las dificultades de aprendizaje del español de la comunidad rumana. Para ello, hemos elaborado una serie de encuestas que pasaremos a través de Internet a los rumanos residentes en Canarias registrados en la Asociación RUMACAN.

Junto a los resultados de las encuestas, utilizaremos para la investigación distintas fuentes escritas, como revistas científicas, publicaciones, textos virtuales, nacionales e internacionales, recogidos en repositorios virtuales. Este estudio puede considerarse como punto de partida de futuras investigaciones relacionadas con la enseñanza del español, no solamente a la comunidad rumana, sino también a todos aquellos colectivos cuya lengua de proveniencia sea una lengua romance.

\section{Marco teórico}

Como hemos mencionado antes, el objetivo principal de esta investigación es detectar y analizar las dificultades de aprendizaje del español por parte de los residentes rumanos. En cuanto a estudios anteriores realizados acerca de este tema, muchos se limitan al lenguaje oral, ya que el lenguaje escrito entraña mayor dificultad de análisis.

Para poder delimitar mejor el tema, realizaremos una revisión de la literatura existente desde dos perspectivas: un análisis comparativo entre el rumano y el español y las dificultades de aprendizaje que suponen las diferencias y similitudes entre las dos lenguas.

En la sociedad actual, existe la creencia de que hay ciertas comunidades de extranjeros que adquieren con mayor facilidad una lengua. Este es el caso de rumanos, italianos, franceses u otros de origen eslavo, que al parecer aprenden de manera más rápida y fácil la lengua castellana. Este hecho podría ser, en algunos casos, parcialmente justificado por la pertenencia al conjunto de lenguas romances. Por otra parte, los estudios de González Faraco y otros (2011) y los de O' Nions (2010) concluyen que esta facilidad de aprendizaje del idioma se debe, en gran medida, al nivel elevado de integración social que tienen los alumnos rumanos, polacos y lituanos. 
Sea cual sea la veracidad de estas afirmaciones, lo cierto es que el rumano y el español son dos idiomas distintos que comparten ciertas características morfosintácticas. En un artículo publicado por Chireac, Serrat y Huguet (2011) se realiza un análisis breve de estos aspectos morfosintácticos. En rumano hay tres tipos de determinante: masculino, femenino y neutro, a diferencia del español, que solo posee dos. Los sustantivos en rumano tienen un género fijo y es el determinante el que posee la flexión y realiza las combinaciones específicas de desinencias. La presencia del género neutro es la que dificulta el aprendizaje, pues en singular los sustantivos tienen forma de masculino y en plural toman formas femeninas. Lo interesante de los sustantivos en rumano es que se diferencian también según el caso. Existen diferencias entre las formas de nominativo o acusativo y las del genitivo y dativo. El vocativo se utiliza en los nombres propios pero también si el sustantivo designa seres humanos:

Fiule! - ¡Hijo!

Otra característica propia del rumano es la aglutinación de los artículos definidos al sustantivo o adjetivo como un sufijo (-a/-le para el femenino singular y plural y -//-i para el masculino singular y plural). La mayoría de las desinencias dependen de este artículo y se construyen de forma distinta dependiendo del caso, en dativo o genitivo. En español, el artículo definido es una palabra separada que precede al sintagma nominal. En cuanto a los artículos indefinidos, al igual que en español, no tienen una forma explícita para el plural y, en la mayoría de los casos, preceden al sustantivo o adjetivo.

Según Madrona y Pisot (2009), existen usos diferentes del artículo determinado entre el español y el rumano. Principalmente, en español se usa entre la preposición y el sustantivo al que acompaña, mientras que en rumano no, salvo si el sustantivo va determinado:

Voy a la discoteca. - Merg la discotecă.

Otra de estas discrepancias en el uso del artículo determinado se encuentra en su uso con los posesivos. En rumano, este artículo sí se usa con los posesivos, sin embargo, cuando el posesivo antecede al sustantivo, no se emplea el artículo determinado, sino el genitival:

Al meu frate a plecat. - Mi hermano se ha ido.

Finalmente, este artículo en rumano, a diferencia del español, sí se utiliza con nombres de países o ciudades y en los títulos que aparecen en obras científicas (diccionarios, atlas, etc.).

En relación a las preposiciones en rumano, uno de los rasgos más representativos es la desaparición de la preposición derivada del latín ad (a, hacia), que marca el dativo. Como medida compensatoria, el dativo posee marcas en los pronombres tónicos de tercera persona. En rumano existen cinco casos gramaticales: nominativo, genitivo, dativo, acusativo y vocativo, que afectan tanto a sustantivos como a adjetivos y pronombres, mientras en español 
solo hay casos gramaticales para los pronombres. En comparación con los pronombres en español, Tamas (2005) recoge una serie de características de los pronombres rumanos:

- tienen formas tónicas y átonas;

- en rumano existen aproximadamente cien pronombres;

- la posición del pronombre objeto directo coincide con la del español;

- el pronombre personal, singular, femenino, forma no acentuada en acusativo o, en pasado compuesto (pasado simple/indefinido) sucede al verbo, Am văzut-o - La vi, pero en presente lo precede, 0 văd - La veo;

- los pronombres posesivos en rumano van detrás del sustantivo:

Tatăl nostru - Nuestro padre;

- en los nombres propios masculinos el genitivo se antepone al mismo y en los femeninos se añade al nombre como un sufijo:

Cartea lui lon - El libro de Juan,

Cartea loanei - El libro de Juana.

Con respecto a los adjetivos rumanos, se destaca la similitud con el español en el uso del comparativo y el superlativo. Del latín magis derivó en rumano mai y en español más y no plus (también del latín) como en francés e italiano. En rumano, plus existe, pero se emplea solamente en la realización de sumas: Trei plus doi - Tres más dos.

Las grandes discrepancias entre el rumano y el español residen en el sistema verbal. Mientras en español existen tres conjugaciones, según la vocal temática del infinitivo, en rumano hay cuatro: -a, -ea, -e, -i/-î. En ambos idiomas cada persona verbal tiene una terminación que indica persona y número. A diferencia del español, en rumano pueden coincidir la $1^{a}$ persona del singular y $3^{a}$ del plural (eu/ei muncesc) o la $3^{a}$ del singular y la misma del plural (el/ei urcă) (Madrona y Pisot, 2009).

En rumano, los modos verbales se dividen en personales e impersonales. Los modos personales son el indicativo, el conjunctiv, el condicional-optativo y el imperativo. El conjunctiv es un modo verbal personal y predicativo que expresa una acción, hecho o estado supuesto, realizable o posible. De esta manera, puede tratarse de una acción deseada, preferida, intencionada o no, demandada o recomendada. Dentro de este modo podríamos incluir el subjuntivo español, aunque el conjunctiv también posee formas verbales declarativas. Este modo se conjuga en dos tiempos, presente y perfecto. Tanto el uno como el otro llevan el morfema específico del conjunctivo, que es la conjunción să. En el tiempo presente se emplea la estructura primer verbo en presente + "să" + presente del segundo verbo. Generalmente las construcciones del conjunctiv comienzan con formas del verbo poder, querer y tener que o necesitar. Esto queda más claro con unos ejemplos: 
Tenemos que ir a Timisoara. - Trebuie să mergem la Timisoara.

No puedo hablar español. - Nu pot să vorbesc spaniolă.

Como se puede ver, al igual que en español, el primer verbo se conjuga según la persona, pero el segundo verbo no queda en infinitivo, sino que también se conjuga.

Los modos impersonales de los verbos en rumano son el infinitivo, el gerundio, el participio y el supino. Aquí la diferencia con el español reside en el infinitivo, que tiene una marca antepuesta al lexema verbal propiamente dicho (a merge-ir), y en que el rumano mantiene la existencia del supino latino. El supino es una forma impersonal y no predicativa del verbo. Se construye de dos maneras: la primera mediante la sustantivación de un verbo (1) y la segunda mediante la preposición de más el participio (2).

1. Mersul pe jos face piciorul frumos.- El caminar embellece la pierna.

2. Mai am mult de mers.- Me queda mucho por caminar.

En español no existe esta forma verbal. Como hemos visto en los ejemplos anteriores, el supino latino en español se expresa mediante construcciones analíticas. Otro de los modos que no tiene equivalencia en español es el presuntivo, que presenta una acción como supuesta o probable. Lo más parecido en español a este modo es el futuro del indicativo.

Oi veni, de-oi avea chef. - Vendré si tendré ganas.

En cuanto a los tiempos verbales, el indicativo rumano tiene seis tiempos verbales, uno para el presente, cuatro para el pasado - el imperfecto, el perfecto compuesto, el pluscuamperfecto y el pasado simple- y uno para el futuro. Mientras en español hay 10 tiempos verbales, incluyendo el condicional, que, como hemos mencionado antes, en rumano es un modo verbal. Aunque parece que esta diferencia hace más fácil la gramática del verbo en rumano, el español solo tiene tres conjugaciones, mientras el rumano posee cuatro conjugaciones distintas y tres verbos auxiliares. De las cuatro formas de pasado, el perfecto compuesto se construye con el verbo tener en presente como auxiliar + el participio. El imperfecto y el pluscuamperfecto son similares a los del español y el pasado simple correspondería al pretérito perfecto, aunque en Rumanía su uso se restringe a algunas regiones.

Asimismo, lorgu (1965) desarrolla la teoría de las áreas laterales de la latinidad, que afirma que en las zonas periféricas como Iberia y Dacia se preservaron expresiones y términos antiguos que en las zonas centrales fueron sustituidas por creaciones nuevas. En sus estudios, también afirma que tanto el rumano como el español conocen dos innovaciones muy características a nivel sintáctico. La primera es la expresión del complemento directo. Cuando se trata de una persona se emplea una preposición entre el verbo y el sustantivo: a en español 
y pe en rumano. Ninguna de las demás lenguas románicas presenta esta derivación. Según el autor, la causa reside en la necesidad de evitar la confusión entre el sustantivo objeto y sustantivo sujeto. La segunda innovación sintáctica a la que hace referencia es la repetición del complemento directo e indirecto expresado por un sustantivo o pronombre: en español, Le di a Juan el libro; en rumano, I-am dat lui loan cartea. La innovación reside en que estas construcciones no existían en latín y actualmente están ganando terreno en la lengua moderna.

Más tarde, en 1968, lorgu añade una tercera innovación que se produce en las dos lenguas. Según él, el rumano y el español son los dos idiomas más predispuestos a la creación de nuevos verbos, si mediante el vocabulario existente el hablante no dispone de medios para expresarse. Mientras las nuevas formaciones verbales en rumano acaban generalmente en -iza, las producidas en español suelen acabar en -ar. La innovación consiste en la libertad que ofrecen estas dos lenguas de crear sin dificultad verbos que en otros idiomas es improbable que existan.

Avanzando en nuestro razonamiento, una vez expuestas las diferencias y similitudes entre el rumano y el español, vamos a analizar la literatura existente acerca de las dificultades de los rumanos como aprendientes de español. Serramitja (2009) ha realizado un estudio sobre los errores que cometen los rumanos en la adquisición de los determinantes del español. Según sus resultados, existen tres errores frecuentes que los rumanos cometen: de omisión, de adición y de concordancia.

Los errores de omisión son aquellos producidos en el uso del determinante por defecto. Ejemplo: Aquí mucha gente se va a Ø (la) disco. Según ella, estos errores se producen a causa de la inferencia de la lengua materna. En rumano, el artículo definido es pospuesto al nombre por sufijación (fratele - el hermano), por tanto, un hablante rumano de español tiene la tendencia de omitirlo.

Con respecto a los errores de adición, son el contrario de los de omisión. Se trata de un tipo de error del determinante por exceso. Ejemplo: Me gusta el $\varnothing$ Begur. La autora afirma que estos errores se explican por la misma razón que los errores de omisión: Ia posposición del artículo definido en la lengua materna.

Finalmente, el último tipo de error que menciona Serramitja (2009: 821) es el error por concordancia. Esta confusión se produce cuando no hay concordancia de género y/o número de un determinante con el sustantivo o núcleo nominal al que acompaña. Ejemplo: El pan se come con algunas comida. Tal y como afirma la autora, esto se produce por las declinaciones nominales con paradigmas muy marcados en rumano, que distinguen género, número y caso.

El problema de la concordancia para los aprendices rumanos es muy recurrente entre los estudios desarrollados al respecto. En la investigación realizada por Martí Puig y Moliner Gar- 
cía (2003) Ilamada "Español para inmigrantes rumanos adultos", se recoge una clasificación de las dificultades más comunes de carácter fonético, léxico y gramatical:

- los verbos irregulares y las conjugaciones de los modos y los tiempos en español

- la pronunciación de c pors

- la pronunciación de s pors sonora

- los acentos y la entonación

- la pronunciación de elle por eye

- la concordancia de género entre artículo y nombre

A su vez, Roesler (2007) realiza una investigación similar, diferenciando entre dificultades fonéticas, gramaticales y léxicas. A diferencia del trabajo realizado por Martí y Moliner, Roesler añade las siguientes dificultades:

- Ia utilización de las preposiciones a, en y de:

Quería venir en España;

- la colocación indiscriminada de los pronombres demostrativos, antepuesta y pospuesta sin valoración:

Las telenovelas esas / las salidas estas;

- la utilización de los pronombres indefinidos o adverbios de negación nada, nadie, ninguno y nunca con verbos en forma negativa:

Nadie no te coge;

- los pronombres del objeto directo e indirecto con respecto a las formas le y lo:

Hay una comida típicamente rumana. Vamos a probarlo;

- el empleo de elementos léxicos del rumano que se aproximan a sus correspondencias españolas y que los rumanos lo integran como parte del español:

Iría por Ungaria.

Según Roesler (2007), la mayoría de las particularidades que se dan en el español hablado por rumanos es resultado de la transferencia de la lengua materna. Por otra parte, su estudio muestra que el contacto que los rumanos tienen con el español latinoamericano a través de la telenovelas emitidas en las cadenas rumanas, en versión original subtituladas, se plasma en la tendencia de los rumanos al seseo y yeísmo. Esta transferencia se debe a las lenguas en contacto.

En concordancia con el estudio realizado por Martí y Moliner, Chireac (2012) analiza los distintos errores verbales que cometen los alumnos rumanos escolarizados en Cataluña. Una 
de las conclusiones a las que llega es que los rumanos que menos tiempo de estancia llevan en España -inferior a 3 años - tienen un alto porcentaje de errores de uso del pretérito perfecto por otros tiempos verbales. En su opinión, esto se debe a que los rumanos confunden el perfecto con el indefinido por la transferencia que se produce de la lengua materna, en la que usan solo el perfecto. Al parecer, en una situación en la que se le exige al hablante rumano elegir entre dos tiempos verbales para expresar una acción perfectiva, este prefiere el pasado sin darse cuenta del error. Ejemplo recogido de su investigación:

\section{¿Cómo celebraste tu cumpleaños el año pasado?}

\section{Hemos comido la tarta y después hemos jugado.}

Con respecto a los verbos ser y estar, Tamas (2005) nos aclara que los verbos auxiliares en rumano no presentan ese emparejamiento, al igual que con haber y tener. Se utiliza la misma forma para las funciones de auxiliar y del verbo predicativo (a fi, a avea). Por ello, un aprendiz de español podría tener dificultades para emplear y entender su uso. Más aun, Cirstea (2006) afirma que la dificultad que presentan los rumanos en el uso de estos verbos no solo reside en tener que elegir entre los dos, sino también en problemas de sintaxis, semánticos y de dominio léxico. El aprendiz debe tener en cuenta el significado, pues los rasgos semánticos propios del adjetivo que le sucede indican cualidades distintas. Según la autora, el uso predicativo de ser y estar genera menos dificultades que el uso copulativo, ya que el aprendiz puede darse cuenta del error sustituyendo los verbos ser por existir y estar por encontrarse. Madrona y Pisot (2009: 103) concluyen que al verbo a fi le corresponden cinco verbos españoles, dependiendo del contexto: haber, ser, estar, tener y hacer.

En cuanto a los errores que afectan el verbo, Cirstea (2006: 270) añade que estos "se producen por tratar los verbos como si pertenecieran a otra conjugación (cantió, escribemos), cambiando la vocal temática y las desinencias (veniendo, hablastes), por la confusión entre las desinencias de tiempos distintos pero próximos formalmente (escribíamos en lugar de escribiríamos) y por el intercambio entre las personas gramaticales". En los verbos irregulares, los errores residen en la alteración de la raíz verbal (sentió). Los verbos que mayor dificultad presentan son aquellos acabados en -ger o -gir. Los errores aparecen cuando el aprendiz desconoce las reglas ortográficas de estos verbos en presente indicativo y en subjuntivo y dan como resultado conjugaciones como cogo o coga (del verbo coger). Los verbos en imperativo también inducen a errores en los aprendices rumanos, quienes generalmente utilizan la forma del presente indicativo de la segunda persona del singular con la desinencia en -s: iComes!

Por su parte, Gràcia (2007) realizó un estudio acerca de la influencia de la lengua materna en la adquisición de una segunda lengua, en este caso el español. Su investigación, basada en un análisis de errores, demostró que los hablantes de rumano como lengua materna producen menos errores de flexión verbal que los hablantes cuya lengua materna es el chino. Entre sus conclusiones, la autora observó que los rumanos concentran la mayor parte de 
los problemas en el uso de las formas personales. Suelen sustituir con frecuencia una forma personal por otra utilizando morfemas de personas en las formas verbales. Los problemas de flexión de persona y número hallados en su estudio están relacionados con el uso de la $3^{a}$ persona del singular en lugar de la $3^{a}$ persona del plural o la $1^{\text {a }}$ del singular. Los errores que se detectan se producen cuando la primera persona tiene desinencia-e/-é.

A: ¿vivías en el campo?

B: sí, pero esto sólo cuatro años, antes estuvo en la ciudad

Por otra parte, demostró que los hablantes rumanos de español cometen mayores errores de confusión de formas marcadas con morfemas de tiempo, aspecto y modo. Estos errores se deben al uso incorrecto de una forma flexionada. En la mayoría de los casos se utiliza el presente por el imperfecto o el perfecto por el pasado compuesto. El uso del presente en los hablantes rumanos no se debe a una dificultad a la hora de conjugar, sino al uso de los tiempos y modos verbales en las frases compuestas, que es diferente en la lengua materna. En frases en las que un nativo de lengua española hubiese utilizado el imperfecto, un hablante rumano utilizaría una forma verbal de presente.

Español: Pregunté si había un diccionario.

Rumano: He preguntado si es un diccionario.

En cuanto a la sustitución del perfecto por el pasado, la autora afirma que se debe al hecho de que el pasado en rumano solo se usa en narraciones escritas; en el lenguaje oral se utiliza el perfecto. Las faltas que los rumanos cometen en el tiempo, aspecto y modo verbal se deben a un uso incorrecto de las formas, como consecuencia del valor, el uso y la sintaxis de los tiempos y modos en la lengua materna.

En el mismo estudio, la autora quiso analizar los errores de orden de constituyentes de la oración producidos por los hablantes rumanos y la influencia de la lengua materna en estos. El rumano, al igual que el español, tiene una estructura de las oraciones declarativas simples, siguiendo el orden SVO (sujeto, verbo, objeto), aunque el español es relativamente más libre y ligado a cuestiones discursivas que a menudo llevan a la confusión del aprendiz de español como lengua extranjera. En el ejemplo que recoge en su investigación, Gràcia (2007: 28) observa que el hablante rumano coloca el objeto indirecto antes que el objeto directo. Según su explicación, esto se debe a que algunos verbos en rumano rigen dos acusativos y que, en este caso concreto, el que equivale al dativo español precede al que sería el acusativo.

\section{Es que tengo un diploma y ahora puedo enseñar a niños pequeños deporte.}

En lo que se refiere a los errores gráficos, Tamas (2005) destaca la confusión de grafemas, la acentuación, la puntuación y los signos de puntuación. Los rumanos tienen cierta dificultad 
para distinguir gráficamente entre los fonemas b y $v$, porque en rumano existen dos sonidos distintos para cada uno. Otra dificultad son los grafemas // y ñ, que no existen en el alfabeto rumano y que producen errores del tipo ninio por niño. Lo mismo pasa con el grafema q, que aunque existe en el alfabeto rumano es poco usual. Los rumanos suelen sustituir este grafema por la k, ya que es fonéticamente más parecida a la $q$ rumana. Pero sobre todo, Ilama la atención la omisión del grafema $h$, que en rumano tiene sonido propio. Por tanto, podemos encontrar palabras escritas por rumanos tales como oja o umor.

A su vez, los rumanos tienen bastantes problemas con la acentuación. La falta de acentuación gráfica en rumano hace que se produzca la omisión de la tilde, sobre todo en palabras monosilábicas.

\section{Se que has hablado con el.}

Otros errores de acentuación pueden aparecer por adición, cuando el aprendiz coloca la tilde según la acentuación de la palabra como en fué, dió, vió. También se da en los sustantivos que en singular no llevan tilde pero que la recibe en plural —exámen-exámenes — o si el sustantivo cambia la sílaba tónica en plural —régimen-régimenes-.

Los rumanos también confunden los pronombres interrogativos o exclamativos con los pronombres relativos. Así pues, podemos encontrarnos con frases escritas como iQue bueno! Los errores de puntuación que más cometen los rumanos están relacionados con las frases interrogativas y exclamativas y, en menor grado, con la diéresis. En rumano, las interrogativas y exclamativas solamente llevan un signo de puntuación al final del enunciado, error que extrapolan al escribir en español. Igualmente, la diéresis en rumano no existe; por tanto, es muy probable que un rumano escriba palabras como antiguedad o aguero.

En relación a la investigación anteriormente nombrada, Uta (2010: 237) ha realizado un estudio acerca de lo que ella denomina el rumañol, como fenómeno de interlengua que se produce entre el rumano y el español hablado y escrito por rumanos. Un aspecto muy particular de este estudio es que realiza un análisis de 20 textos, en su mayoría anuncios publicados en las calles de Alcalá de Henares, Madrid y Coslada, escritos en rumano o español. A continuación veremos algunos de los errores más destacados de este estudio:

- mal uso de la preposición de;

- alternancia de las formas correctas e incorrectas de tipo: viajere/viajero:

El viajere debe confirmar la fecha.../En el caso de que el viajero...;

- la acentuación:

El billete de vuelta quedara vigente 6 meses de la fecha de expedicion;

- conjugación de los verbos:

En el caso de que el viajero no se presenta al embarque, el billete pierde; 
- concordancia sujeto verbo, los signos de interrogación y exclamación, los acentos y la estructura de la frase:

¿Extranjeros, quieres ver tu television por satélite de tu país. LLamame.

Lo más Ilamativo es que en las producciones realizadas por rumanos en rumano escrito se han introducido palabras del español que tienen su equivalente en rumano. Por ejemplo, en el siguiente anuncio se alquila el salón de una casa: Inchiriezi loc pe salón liber din orice momento...rog seriozitate. Pret- 100€+ 50 Fianta. En rumano, la palabra salón tiene su traducción en sufragerie, por lo que se trata de una permutación del español para hacer la comunicación más fácil. En cuanto a la palabra Fianta, bajo este aspecto no existe ni en rumano ni en español; se trata de una palabra española que ha sido derivada según las reglas gramaticales rumanas, lo que en lingüística Ilaman los expertos como el mecanismo de préstamo de la interlengua.

Como hemos podido observar hasta este punto, entre el rumano y el español existen tanto similitudes como diferencias. Hemos constatado cómo algunos investigadores han realizado comparativas entre las dos lenguas con el fin de averiguar y de hallar soluciones a los errores que cometen los rumanos en español. Así, lo que ha quedado patente a partir de todas las investigaciones es que en mayor o menor medida la lengua materna influye en el aprendizaje de una lengua extranjera. A modo de resumen, los errores más comunes y más presentes en las investigaciones acerca del aprendizaje del español por parte de los rumanos están relacionados con la concordancia en género y número entre sustantivo/adjetivo y determinante/artículo y las conjugaciones verbales, sobre todo de pasado e irregulares. De la escasa literatura existente acerca del español escrito por rumanos, hemos constatado que, a parte de los errores que se cometen a nivel oral y que se extrapolan a nivel escrito, también se comenten fallos de acentuación y puntuación. Según Selinker (1972), al igual que el hablante nativo, el aprendiz de una lengua extranjera desarrolla una gramática mental de la lengua que está adquiriendo. Esta se va modificando y haciendo más o menos compleja según el nivel de competencia adquirida en la lengua extranjera. A lo largo del proceso de exposición a la segunda lengua el aprendiz realiza una serie de errores similares a los que producen los que se encuentran en su mismo nivel de interlengua. La causa de estos errores puede ser la influencia de la primera lengua o la generalización excesiva de reglas adquiridas.

\section{Método de investigación}

\subsection{Metodología}

Para este estudio, hemos decidido emplear una metodología cuantitativa. Según Corbetta (2003), en la investigación cuantitativa el objeto de análisis es una realidad observable, que pretende establecer una relación deductiva entre la teoría y la hipótesis. A través de la validación de la hipótesis, se comprueba la relación causa-efecto entre los fenómenos de estudio. 
Más aún, Bisquerra (1989: 236) afirma que este tipo de investigación tiene capacidad de predicción y generalización dentro del universo estudiado.

Para llevar a cabo la investigación, hemos elaborado una encuesta, que según Latorre, Del Rincón y Arnal, (1996: 182) "es un método de investigación basado en una serie de preguntas dirigidas a sujetos que constituyen una muestra representativa de una población con la finalidad de describir y/o relacionar características personales, permitiendo así generalizar las conclusiones".

La decisión de realizarla a través de Internet ha sido por varios motivos. En primer lugar porque así hemos logrado abarcar a participantes de toda Canarias. En segundo lugar, hemos logrado superar las inconveniencias del trabajo de campo. Tal y como afirma Núñez Villuendas (2005), existen variables que influyen en el trabajo de campo, como el sexo del entrevistador - que puede intervenir en la tendencia sexista de las respuestas-, cuando el entrevistado conoce previamente el entrevistador, si el estilo de la encuesta es demasiado formal, el comportamiento del entrevistador, la ideología política o las preguntas relativas al grado de conocimiento del entrevistado. Todo ello puede llevar a la crispación o la negación del entrevistado de participar en la encuesta. Mediante el estilo de recopilación de información online, hemos logrado que los participantes, de manera anónima, rellenen el formulario sin las barreras e inconvenientes de la entrevista personal. La plataforma Online Encuesta, con la que hemos trabajado, ofrece varias ventajas sobre las demás. Se trata de un programa que abarca un número ilimitado de preguntas, a la vez que ilimitado de participantes. El tipo de preguntas que se puede escoger es variado, dependiendo del objetivo que persigue la encuesta. Otra de las ventajas destacadas es que se puede redactar en varios idiomas. Este aspecto fue fundamental, ya que era necesario escribirla en rumano. La evaluación de las respuestas se realiza en tiempo real, mediante gráficos y porcentajes. También ofrece la opción de ver las respuestas por participante y descargar los datos en diferentes formatos.

La primera parte de la encuesta es un estudio sociológico o encuesta descriptiva, que tiene el objetivo de recopilar las características de la población. Hemos introducido aquí las variables socio-demográficas, tales como la edad, el sexo, los años de residencia, etc. Está redactada en rumano, ya que hemos contemplado la posibilidad de que haya participantes que desconocen el español. La segunda parte es una encuesta explicativa, en la que los sujetos poseen valores de variables independientes, es decir, cada respuesta es una única variable pero que en conjunto permite confirmar las relaciones causales. Para ello, hemos utilizado una serie de preguntas de selección múltiple que plantean posibles problemas gramaticales. Acerca de este tipo de evaluaciones, Ebel (1979: 116) considera que: “... se adapta a la medición de los resultados educativos más importantes: conocimiento, comprensión y buen juicio; a la habilidad de resolver problemas, de recomendar acciones apropiadas y hacer predicciones. Casi cualquier comprensión o habilidad que pueda medirse con otras formas de evaluación puede medirse también con exámenes de opción múltiple”. 
Más aún, Leuba (1986) afirma que las preguntas de opción múltiple no solo pueden asociarse a memorizaciones sencillas, sino que también a través de ellas se pueden medir actividades intelectuales complejas, como la creatividad, la capacidad de síntesis o resolución de problemas.

Para la construcción de la encuesta explicativa, hemos optado por incluir preguntas híbridas que combinan la opción múltiple con la de rellenar huecos. Este tipo de preguntas de respuesta restringida ha sido utilizado en la enseñanza de lenguas como estrategia para desarrollar la comprensión escrita. Según Amérigo (1993) esta tipología de preguntas facilita considerablemente el análisis posterior de los datos a la vez que facilita la respuesta a individuos con dificultad de expresión. Teniendo en cuenta que los participantes de esta encuesta se encuentran en distintos niveles lingüísticos, consideramos oportuno emplear este método. Por otra parte, García-Beltrán y otros (2006) afirman que las pruebas de respuesta objetiva, cerrada o tipo test, tienen como ventaja el que se puedan diseñar para comprobar muchos tipos de objetivos. Según ellos, el obstáculo de este tipo de pruebas reside en la dificultad de su elaboración, pues requiere mucho tiempo e ingenio.

Finalmente, para la detección de las dificultades tendremos en cuenta las siguientes variables: otras lenguas habladas y el tiempo de residencia en España. Los resultados que pretendemos obtener con estas mediciones reflejarán el grado de influencia que tiene el conocimiento de otras lenguas en el aprendizaje del español y si existe una relación proporcional entre el tiempo de inmersión en la lengua y el nivel de adquisición.

\subsection{Perfil de los participantes}

Como hemos mencionado anteriormente, la recopilación de los datos de este estudio se ha realizado íntegramente a través de una encuesta online, por tanto, no hubo una selección de los participantes. La muestra se compone de 58 encuestados, residentes en Canarias y registrados en la asociación RUMACAN (Rumanos en Canarias) que han tenido que hacer la inmersión lingüística en español. Se trata de una muestra representativa, porque abarca un amplio espectro de edades comprendidas entre los 18 y 60 años. Dentro del estudio sociológico hemos preguntado por el sexo, la edad, el nivel máximo de estudios alcanzado, el tiempo de residencia en España, lenguas habladas, el nivel de español que poseen, cómo han aprendido el español y, finalmente, si sabían español antes de llegar a España. Para diseñar el perfil de los encuestados, tendremos en cuenta todas las variables anteriores.

Del total de la muestra, el 79,3\% son mujeres y el 20,7\% varones. La edad de los participantes oscila entre los 18 y los 60 años, siendo el intervalo más representativo el comprendido entre los 26 y los 35 años. 


\section{GRÁFICO 1}

Perfil de los participantes por edad

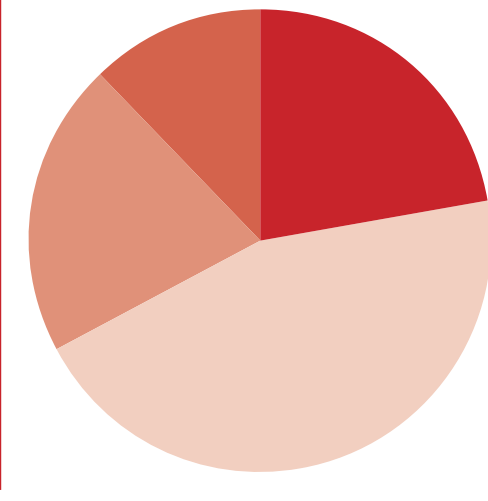

$18-25: 22.41 \%$
$26-35: 44.83 \%$
$36-45: 20.69 \%$
$46-60: 12.07 \%$

Fuente: Elaboración propia

En cuanto al perfil académico de los encuestados, el 50\% posee un título universitario y el $44,8 \%$ ha finalizado estudios de bachillerato. De los datos restantes, el 3,4\% afirma haberse titulado en formación profesional, mientras que el 1,7\% ha alcanzado estudios de enseñanza secundaria obligatoria.

\section{GRÁFICO 2}

Perfil de los participantes por nivel académico
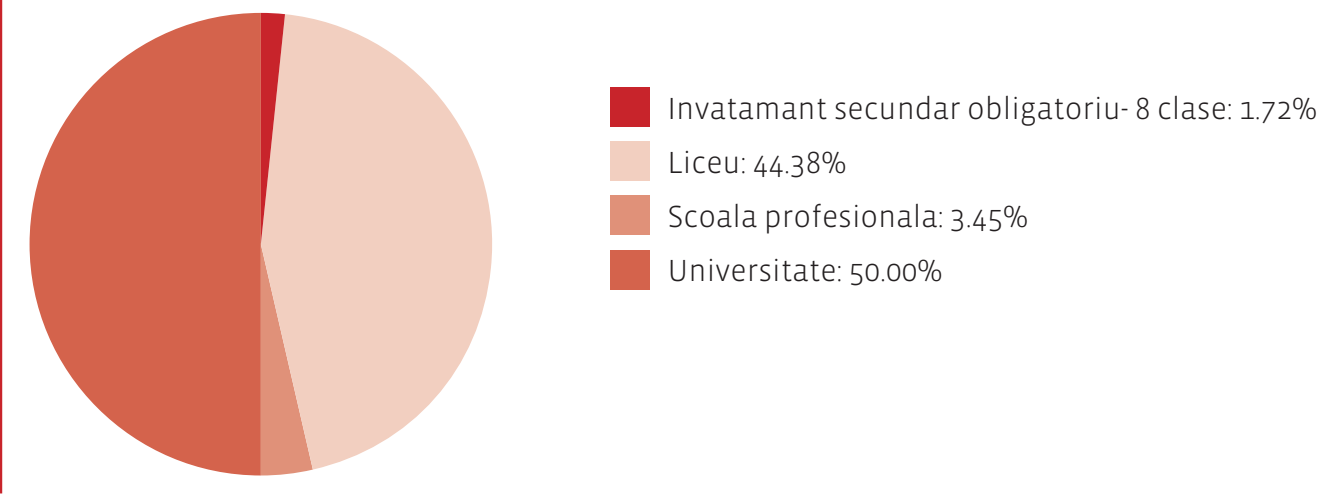

Otro aspecto importante que hemos considerado es el tiempo de residencia en España. De los 58 participantes, el 12,3\% lleva menos de 1 año de residencia, el 24,6\% lleva entre 1 y 5 años y el $35,1 \%$ lleva entre 6 y 10 años. Asimismo, un porcentaje bastante alto, el 21,1\%, lleva más de 10 años en España y el 7\% reside desde hace más de 16 años en nuestro país (véase el gráfico 3).

En relación con los idiomas que los participantes hablan, a parte del rumano y el español, el $81 \%$ afirma hablar inglés, el 31\% habla francés y el 25,9\% habla italiano. Además, el 12,1\% conoce el alemán y el 1,7\% habla ruso. Del 15,5\% restante, los participantes han afirmado hablar turco, húngaro, hebreo, catalán o portugués. Solamente 3 participantes han contestado que no hablan ningún otro idioma (véase el gráfico 4). 


\section{GRÁFICO 3}

Perfil de los participantes según el tiempo de residencia en España
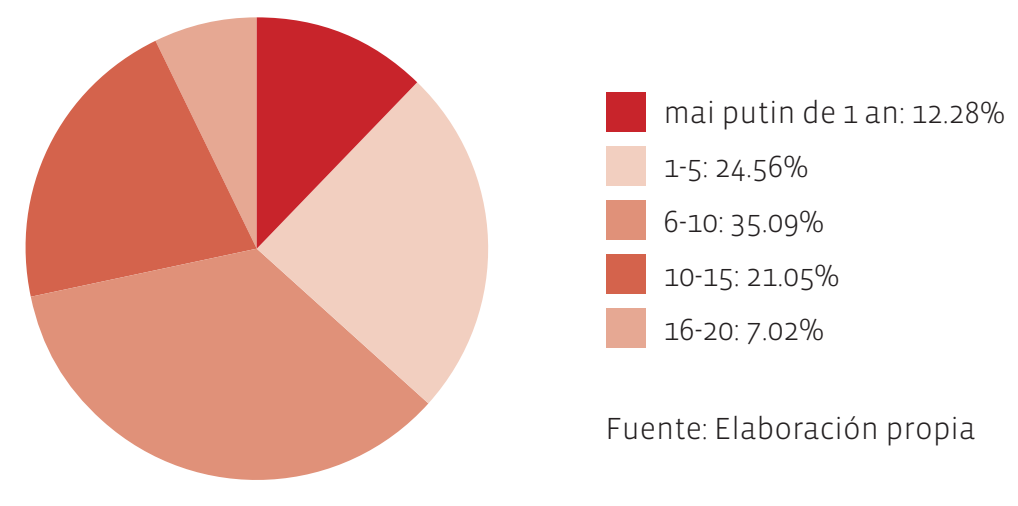

Fuente: Elaboración propia

\section{GRÁFICO 4}

Perfil de los participantes según idiomas hablados

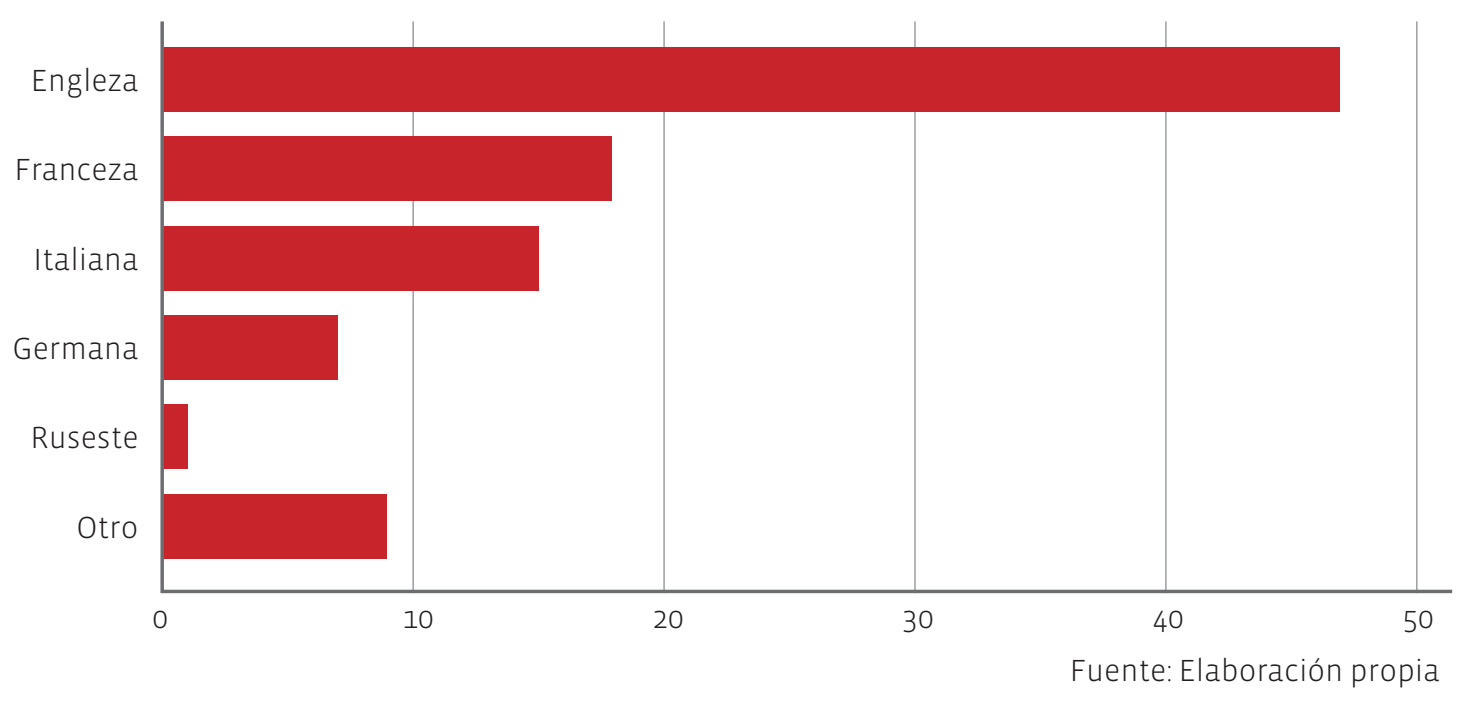

A su vez, hemos preguntado por el nivel de español que la muestra posee. El 50\% domina muy bien el español, el 43,1\% lo entiende y habla bien y el 6,9\% lo entiende y habla con cierta dificultad. Ninguno de los encuestados ha afirmado no entender o no hablar el español (véase el gráfico 5).

En cuanto a la manera en la que han aprendido el idioma, más de la mitad, el 54,4\%, afirma haber aprendido de manera autónoma. El 24,6\% lo ha aprendido en la escuela, mientras el $5,3 \%$ ha acudido a una academia privada y solamente el 1,8 \%ha tomado clases particulares de español. El restante 14\% afirma haber aprendido esta lengua a través de la televisión, en la calle o en la universidad. Del total de encuestados, el 73,2\% afirma haber llegado a España sin saber el idioma. Este último dato es significativo, porque se pueden constatar los errores reales de los rumanos en un contexto de inmersión. 


\section{GRÁFICO 5}

Perfil de los participantes según el dominio del español

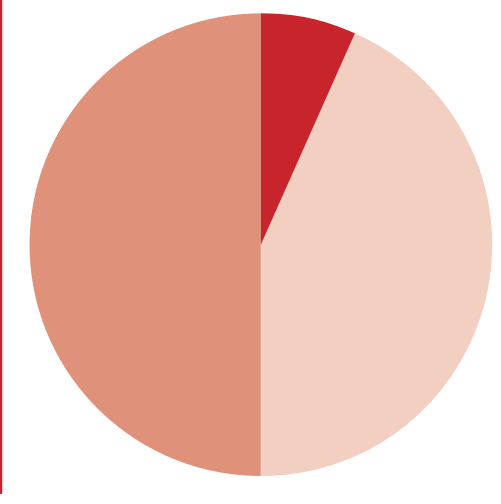

Inteleg si vorbesc putin: $6.90 \%$

Inteleg si vorbesc bine: $43.10 \%$

Domin foarte bine: $50.00 \%$

Fuente: Elaboración propia

Acerca del aprendizaje de otro idioma existe multitud de teorías. Krashen (1982) hace esta aseveración sobre el proceso de adquisición-aprendizaje. Afirma que los adultos tienen dos maneras de desarrollar una competencia lingüística en otro idioma. La primera es la adquisición, un proceso natural, similar al que los niños realizan al aprender la lengua materna. Se trata de un desarrollo inconsciente; los aprendices no suelen ser conscientes de la adquisición de la lengua, pero sí del uso de la lengua como vehículo de comunicación. Según el autor, a través de este proceso se internalizan de manera inconsciente las reglas por las que se rige el idioma adquirido. El hablante será capaz de identificar un error sin conocer las reglas gramaticales que se hayan incumplido.

La segunda manera de adquirir un idioma es a través del aprendizaje. Krashen utiliza el término aprendizaje para aquella adquisición del idioma que se realiza a través de la formación. Es decir, el aprendiz conoce las reglas que rigen el idioma y es consciente de la estructura por la que este se rige.

\section{GRÁFICO 6}

Perfil de los participantes según la manera de aprender el español

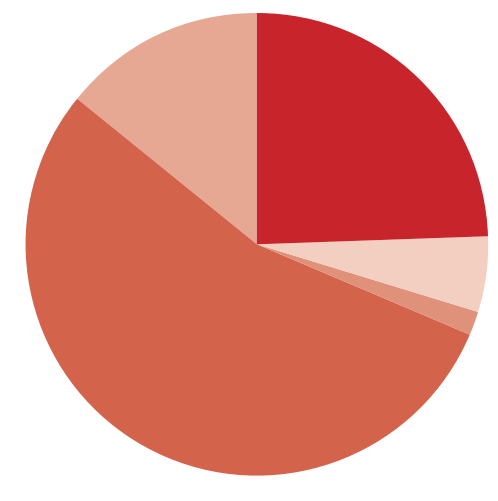

\footnotetext{
La scoala: $24.56 \%$

La o academie privata: 5.26\%

Ore particulare: $1.75 \%$

Singur/a: $54.39 \%$

Otro: $14.04 \%$
}

Fuente: Elaboración propia 


\subsection{Instrumentos}

En el tipo de encuestas explicativas, los sujetos poseen valores de variables independientes, es decir, cada respuesta es una única variable pero en su conjunto permiten confirmar las relaciones causales. La formulación de las preguntas de esta encuesta la hemos realizado tras haber analizado la literatura relativa a las dificultades de los rumanos en el lenguaje oral español. Para la búsqueda de los estudios existentes hemos utilizado distintas fuentes escritas, como revistas científicas, publicaciones, textos virtuales, nacionales e internacionales, recogidos en repositorios virtuales, como Acceda, Arts \& Humanities, Dialnet, Bibliotecas virtuales (del Instituto Cervantes y de varias universidades), Tesis Doctorales en Red (TDR), etc.

Para el análisis hemos medido el conjunto de respuestas de la muestra en relación a ocho problemas gramaticales más comunes: la concordancia entre artículo determinado e indeterminado y el sustantivo, la concordancia entre el adjetivo y sustantivo en cuanto a género y número, la concordancia entre sujeto y verbo, el uso del verbo haber como auxiliar en la formación del pretérito perfecto compuesto, el uso del subjuntivo en oraciones subordinadas sustantiva y adjetiva, la conjugación del verbo haber indicativo, pretérito imperfecto, la pasiva refleja y el uso del dígrafo rr. En total se realizaron diecinueve preguntas, ocho en la parte del estudio sociológico y once en la encuesta explicativa.

Para la elaboración de la encuesta hemos utilizado la plataforma Online Encuesta, que permite crear encuestas personalizadas mediante cuestionarios de evaluación, priorización, preguntas abiertas, medio abiertas o cerradas. Una vez elaborada, se obtiene un enlace directo que puede compartirse con los participantes potenciales por correo o a través de una página web. Tras la iniciación del periodo de encuesta, los datos recibidos pueden ser evaluados y analizados en tiempo real. Los resultados se muestran directamente en línea, de forma gráfica y cuantitativa. Además, existe la opción de descargar los datos almacenados en formatos.pdf, .csv o.spss, para trabajar con ellos de manera independiente. Para este estudio, hemos compartido el enlace de la encuesta a través de las redes sociales, en la plataforma de la Asociación de Rumanos en Canarias.

\subsection{Procedimiento}

En el diseño de evaluación, se procedió, en primer lugar, a realizar una exhaustiva revisión bibliográfica acerca de la enseñanza del español a rumanos y de las dificultades que estos presentan en su aprendizaje. Al tratarse principalmente de literatura sobre el lenguaje oral, hemos decidido extrapolar estas dificultades al lenguaje escrito y, a la vez, comprobar posibles nuevos problemas. Para la recopilación de las investigaciones, como hemos mencionado antes, hemos buscado tanto en los repositorios virtuales nacionales como internacionales. 
Una vez seleccionadas y adaptadas las preguntas, se realizó un cuestionario en formato online y se distribuyó a través de las redes sociales a la Asociación RUMACAN. La encuesta permaneció activa durante un mes de duración, en la que contestaron un total de 58 participantes. Se procuró que entre los participantes hubiese heterogeneidad de sexo, edad y provincia de residencia. Las dificultades para lograr esta heterogeneidad residen en el formato de la encuesta y en el número de posibles participantes en ella. Posteriormente, se comenzó a analizar las principales dificultades de los rumanos como aprendientes de español. Mediante el uso de programas de análisis cuantitativo, como Excel y SPSS, hemos extraído los porcentajes de las respuestas y hemos diseñado gráficos explicativos que ofrecen una visión global de la situación.

\subsection{Resultados}

Presentaremos los resultados en función de los distintos problemas gramaticales planteados. Todos los resultados reflejan los hallazgos encontrados en esta investigación. Analizaremos las distintas respuestas haciendo referencia a dos de las variables seleccionadas en la escala: otras lenguas romances habladas y el tiempo de residencia en España. Consideramos solamente estas variables por la posible transferencia entre las distintas lenguas y para saber si una mayor exposición a la lengua castellana influye en su dominio.

\subsubsection{La concordancia entre el artículo determinado e indeterminado y el sustantivo}

La primera pregunta de la encuesta explicativa pretende averiguar si los aprendices rumanos realizan la concordancia entre el artículo indeterminado un y el sustantivo trauma. Del total de los encuestados, el $67,3 \%$ ha realizado correctamente la concordancia, mientras que el $32,7 \%$ ha realizado la concordancia con el artículo indeterminado una. Esto ocurre porque en rumano los sustantivos acabados en a pertenecen al género femenino y, por tanto, hay una posibilidad de incurrir en el error de realizar la concordancia en femenino. Se trata de un porcentaje significativo, ya que uno de cada tres encuestados tiene tendencia a recurrir al rumano para determinar el género de los sustantivos en caso de duda.

Por otra parte, del total de los aciertos, el 22\% ha afirmado saber hablar francés. Al igual que en español, la palabra francesa traumatisme es de género masculino, por lo que podemos suponer que aquellos que han contestado correctamente podrían haber recurrido al francés para determinar el género. Para el $17 \%$ de los aciertos puede que esta transferencia haya ocurrido del italiano, ya que este porcentaje afirma saber el idioma. En italiano, al igual que en español o francés, la palabra trauma es de género masculino. Finalmente, consideramos importante destacar que el $\mathbf{1 8 \%}$ de los que han contestado de manera errónea no hablan ni el francés ni el italiano. 
En cuanto a la relación entre las respuestas correctas y el tiempo de inmersión en la lengua, no hemos encontrado indicios fiables que determinen que a mayor residencia en España más porcentaje de acierto.

\section{GRÁFICO 7}

La concordancia entre el artículo indeterminado y el sustantivo

La enfermedad de su padre fue ...... trauma para ella.

una

un

la

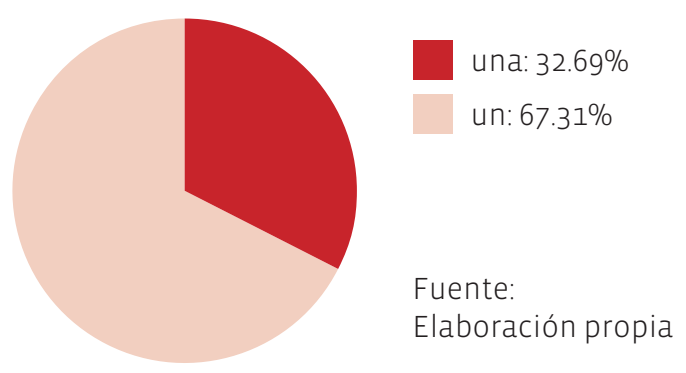

La segunda pregunta del cuestionario la hemos hecho para determinar si los aprendices rumanos de español realizan la concordancia de género y número entre el artículo determinado los y el sustantivo problemas. Como podemos observar en el gráfico siguiente, el $86,5 \%$ de los encuestados realizó de manera correcta la concordancia. Al igual que en el caso del artículo indeterminado, las respuestas incorrectas pueden deberse a la transferencia de género y número del rumano. También en este caso, tanto en italiano como en francés o portugués, el sustantivo problema es de género masculino. Un 90\% de los participantes que han contestado de manera errónea desconoce estos idiomas.

En cuanto a la relación entre el tiempo de inmersión y las respuestas incorrectas, se produce una cierta paradoja. La mayoría de los encuestados que no han realizado la concordancia de manera correcta lleva más de 6 años en España. Este error puede ser causa de una fosilización del error en la concordancia. Habría que recordar que un alto porcentaje de los encuestados afirma haber aprendido de manera autónoma, por lo que la corrección de errores no se ha producido en las fases iniciales de aprendizaje.

\section{GRÁFICO 8}

La concordancia entre el artículo determinado y el sustantivo

\section{Todos.... problemas que tengo se resolverían con} dinero*

los
las
la

$\bigcirc$ el

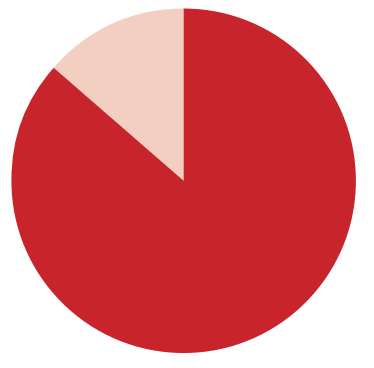

IOS: $86.54 \%$ las: $13.46 \%$

Fuente: Elaboración propia 


\subsubsection{La concordancia entre sustantivo y adjetivo}

La tercera pregunta de la encuesta pretende averiguar si los aprendices rumanos de español realizan correctamente la concordancia entre el sustantivo y el adjetivo. En rumano, al igual que en español, esta concordancia se realiza tanto en número como en género. En la pregunta que hemos realizado, pretendíamos que los encuestados contestaran con la forma escrita del adjetivo aburrida en concordancia con el sustantivo película. Según los datos recogidos, un $80,7 \%$ de los participantes han elegido la forma correcta del adjetivo. Habría que destacar que el $60 \%$ de los que han contestado de manera errónea desconocen cualquier otro idioma romance.

Por otra parte, al realizar esta pregunta queríamos saber si los aprendices rumanos conocían la forma correcta de escribir el adjetivo aburrida. Trataremos el problema de la utilización correcta del dígrafo rr más adelante. Aunque habría que mencionar, como en el caso anterior, que la mayoría de las respuestas incorrectas las han proporcionado rumanos con un tiempo de residencia mayor a 6 años. A diferencia de los problemas de concordancia entre el artículo y el sustantivo, en este caso, es posible que la mayoría de los aprendices rumanos no hayan adquirido la forma gráfica del adjetivo aburrida por haber aprendido el idioma a través de la oralidad.

\section{GRÁFICO 9}

La concordancia entre sustantivo y adjetivo

La película nos gustó porque no era nada ....... **

aburrido

aburrida

aburida

aburido

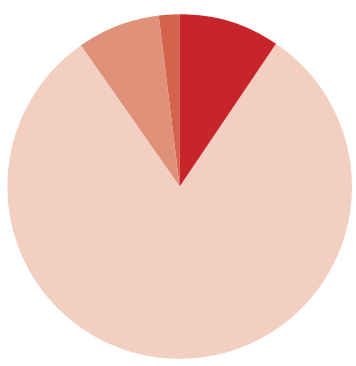

aburrido: $9.62 \%$ aburrida: $80.77 \%$ aburida: $7.69 \%$ aburido: $1.92 \%$

Fuente: Elaboración propia

\subsubsection{La concordancia entre sustantivo y determinante}

En la siguiente pregunta, hemos querido saber si los rumanos aprendices de español tienen dificultades para establecer la concordancia entre el determinante indefinido bastantes y el sustantivo alumnos. En rumano, el determinante bastante se corresponde al adjetivo o adverbio destul. Desde el punto de vista morfológico, destul es un adjetivo cuando va acompañado por un sustantivo y, en este caso, como en español, concuerda en género y número. El problema ocurre cuando es un adverbio, ya que en rumano va seguido de la preposición de. En el supuesto que hemos planteado en la encuesta, el problema reside en la detección de la función morfológica; si se trata de un determinante que 
acompaña al sustantivo siempre se hará la concordancia, pero si se trata de un adverbio de cantidad, la concordancia no existe. Al traducir la frase al rumano, muchos aprendices cometerían el error de asociarlo a un adverbio y, por tanto, no realizar la concordancia. Otra explicación posible puede residir en el rasgo fónico de aspiración de la/s/ en posición final de la palabra en la modalidad lingüística hablada en Canarias. Al tratarse de hablantes que han aprendido el idioma de manera autónoma, es posible que se haya producido una transferencia equívoca y que el hablante reproduzca en la manera escrita lo aprendido de manera oral.

Por otra parte, existe la posibilidad de la comparación entre el francés y el italiano con el español a la hora de construir las frases. En francés, el adverbio o adjetivo assez no cambia de forma, independientemente de la función morfológica. Es posible, por tanto, pensar que un rumano con conocimientos morfológicos del francés extrapole la norma al español. En cuanto al italiano, cambia completamente el morfema según si es adverbio o adjetivo; en este caso un conocedor del italiano no podrá hacer comparativa alguna.

En la relación que se establece entre el tiempo de inmersión y las respuestas correctas, la mayoría de los que han contestado de manera errónea llevan más de 6 años en España, al igual como ocurre en resultados anteriores.

\section{GRÁFICO 10}

La concordancia entre sustantivo y determinante

En esta clase hay ...... alumnos que ya ...... español.*

bastante, sabe

bastantes, saben

bastante, saben

bastantes, sabe

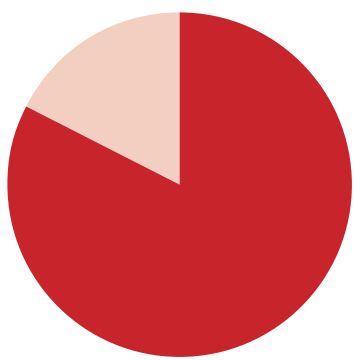

bastantes, saben $82.69 \%$

bastante, saben: $17.31 \%$

Fuente: Elaboración propia

\subsubsection{La concordancia entre sujeto y verbo}

Como hemos podido observar en el gráfico anterior, la pregunta planteaba dos dificultades. La segunda de ellas era la concordancia entre el sujeto alumnos y el verbo saben. Por lo que se puede apreciar de los resultados, la conjugación de este verbo en presente del indicativo no presenta ninguna dificultad para los participantes. Estos resultados concuerdan con los encontrados en la literatura escrita acerca de las dificultades en los tiempos verbales que presentan los rumanos. Recordemos que las mayores dificultades se hallan en los tiempos pasados de los verbos tanto regulares como irregulares, según afirman Martí Puig y Moliner García (2003). 


\subsubsection{Los tiempos verbales. Haber como auxiliar en la formación del pretéri- to perfecto compuesto}

En la siguiente pregunta hemos querido saber si el pretérito perfecto compuesto supone un problema para los rumanos. En concreto, nos hemos centrado en la concordancia entre el auxiliar del verbo haber y el sujeto, como parte de esta forma verbal de pasado. En español este tiempo verbal se encuadra dentro de las formas compuestas del indicativo. Según la RAE (2010), el pretérito perfecto compuesto denota una acción o un estado de cosas anteriores al momento en que se habla, vinculado con el presente. Se forma con el presente del verbo auxiliar haber y el participio del verbo que denota la acción, en este caso el verbo poder. Esta forma verbal suele asociarse a hechos del pasado inmediato que prolongan su influencia hasta el presente.

En rumano, el perfecto compuesto es un tiempo verbal también del indicativo, pero con la particularidad de expresar una acción pasada y finalizada en el momento del habla. Parecido al español, se crea a partir de formas específicas del verbo tener como auxiliar + el participio del verbo conjugado. Por tanto, parecería obvio que un rumano no tendría mayores problemas para contestar a la pregunta.

Los resultados, en cambio, demuestran que un 26,92\% de los encuestados han realizado la concordancia de manera errónea. En la frase que hemos planteado, el sujeto es la cortina de humo y por los líquidos inflamables es un complemento preposicional del adjetivo producida. La confusión en la concordancia entre el verbo y el sujeto reside en la discriminación del mismo. Es decir, un hablante rumano debe distinguir cuál es el sujeto de la frase. Un 73,08\% ha elegido como sujeto la cortina de humo y ha realizado la concordancia en singular, mientras un $19,23 \%$ ha considerado como sujeto los líquidos inflamables y la realizaron en plural. Otra de las razones de esta confusión puede residir en la estructura de la frase. El complemento preposicional es el sintagma más próximo al verbo que debían conjugar, por tanto, al estar en plural, lleva de manera errónea a la concordancia en plural. El 5,77\% de los encuestados también ha dado una forma de plural, pero de primera persona. Posiblemente, hayan realizado la concordancia en plural por las mismas razones que el 19,23\%. El porcentaje más bajo, el 1,92\%, ha contestado con la forma verbal del auxiliar haber de segunda persona del singular. Este error podría ser causa de la poca exposición al idioma, ya que la totalidad de los encuestados que ha elegido esta opción tienen entre 1 y 5 años de residencia en España.

En la relación entre los idiomas hablados y las respuestas acertadas, un 56,9\% afirma saber inglés y el 22,4\% habla francés e italiano. En inglés, al igual que en español, el present perfect tense se construye mediante el presente del verbo to have (tener) y el participio y se refiere a acciones que han sucedido en un pasado reciente y que guardan alguna relación con el presente, a diferencia del rumano. En francés, en cambio, hay dos formas de construir el passé composé, con los verbos avoir (tener) y être (ser) como auxiliares más el participio. 
Al igual que en rumano, este tiempo verbal se utiliza para acciones ya terminadas y equivale al pretérito perfecto simple del español. Por tanto, existe la posibilidad de que la mayoría de los que han realizado de manera correcta la concordancia hayan extrapolado las propiedades del perfecto compuesto del francés. A la vez, la mayoría de los que han contestado de manera errónea afirmó saber solamente inglés o desconocer otro idioma. En definitiva, existen pocas probabilidades de que las respuestas erróneas sean a causa de una interferencia con otro idioma que no sea el rumano.

Finalmente, al analizar la relación entre el tiempo de inmersión lingüística y las respuestas correctas, hemos descubierto que la mayor parte de los encuestados que han contestado correctamente llevan más de 6 años en España.

\section{GRÁFICO 11}

Los tiempos verbales. Haber como auxiliar en la formación del pretérito perfecto compuesto

\section{La cortina de humo producida por los líquidos} inflamables ....... podido verse desde lejos.*

han
ha
hemos
has

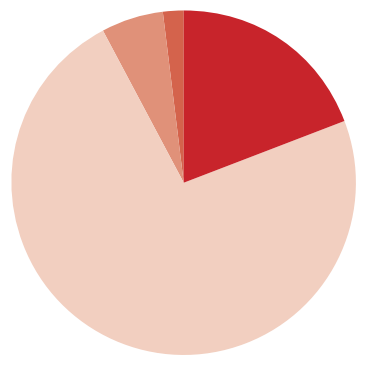

\subsubsection{La pasiva refleja}

En la siguiente pregunta hemos querido averiguar si los hablantes rumanos de español conocen la diferencia entre las oraciones de pasiva refleja y las impersonales. No hemos preguntado directamente, aunque les hemos pedido que realicen la concordancia entre el sujeto y el verbo, si es que la hubiese.

Según la RAE (2010), en las oraciones de pasiva refleja la forma se precede a un verbo en forma activa en tercera persona del singular o plural. Suele ir acompañado de un elemento nominal generalmente pospuesto, que funciona como su sujeto gramatical. Si el sujeto lleva determinante puede ir antepuesto, como es nuestro caso. Por tratarse de una forma de pasiva, solamente se da con verbos transitivos. Al igual como puede aparecer en la pasiva refleja, en la oración impersonal el verbo se encuentra en tercera persona del singular. Las oraciones impersonales carecen de sujeto gramatical y se pueden construir con verbos intransitivos, verbos copulativos, verbos transitivos que llevan complemento directo de persona precedido de la preposición a e, incluso, con verbos en voz pasiva. No se debe poner el verbo en plural cuando la oración impersonal lleva un complemento directo plural, pues la concordancia de número solo se da entre el verbo y el sujeto. 
En la oración de pasiva refleja que hemos propuesto, el sujeto de la oración es el sintagma nominal varios ejemplares gratuitos. Al tratarse de un sujeto en tercera persona del plural, el verbo debería concordar en número y persona. Como podemos ver en el gráfico, un $80,77 \%$ de los encuestados ha realizado la concordancia correctamente, mientras el 19,23\% restante ha elegido la forma verbal de tercera persona del singular. Existe la posibilidad de que este porcentaje haya considerado que la oración no tiene sujeto, por tanto, se trataría de una oración impersonal.

En rumano, la pasiva refleja se introduce mediante el pronombre reflexivo se, al igual que en español. La diferencia es que en rumano la pasiva refleja se extiende a todas las personas. La marca de pasiva refleja se en rumano solamente se utiliza para la tercera persona del singular y plural. Las desinencias cambian según número y persona; mă, ne y te, vă, para la primera y segunda persona singular y plural. Esta podría ser la causa de la confusión producida en las respuestas de los encuestados. Al tratarse de un pronombre que introduce tanto el singular como el plural, el hablante rumano puede optar por elegir bien la forma verbal de singular o la de plural sin tener en cuenta el sujeto de la frase.

En cuanto a la oraciones impersonales con se en rumano, la modalidad más frecuente es la de expresar el valor impersonal a través de verbos reflexivos. Los verbos reflexivos impersonales se construyen con el pronombre en acusativo se solamente en tercera persona del singular. De la misma manera que en español, es la omisión del sujeto la que marca la categoría de oración impersonal. En conclusión, los errores cometidos posiblemente a causa de una transferencia del rumano al español con respecto a las oraciones impersonales se deben a la atribución del sujeto sintagma nominal varios ejemplares gratuitos como complemento directo y, por consecuente, considerar el sujeto como omitido.

En relación a la variable tiempo de residencia en España, al igual que en casos anteriores, paradójicamente, la gran mayoría de los participantes que contestaron de manera errónea afirman llevar más de 6 años en inmersión. En cuanto a la variable otros idiomas conocidos, desde el inglés no puede existir una transferencia, porque en este idioma la oración pasiva refleja no existe. En francés, la pasiva refleja se construye con el pronombre on más el verbo en tercera persona del singular. En este caso, sí se podía haber producido una interferencia, ya que posiblemente un hablante rumano de francés haya podido considerar utilizar estrictamente la tercera forma del singular. Esta posibilidad es muy remota, pues solamente el 5,17\% de los participantes que han contestado de manera errónea afirman conocer este idioma (véase el gráfico 12).

\subsubsection{Tiempos verbales. Conjugación del verbo haber indicativo, pretérito imperfecto}

En la siguiente pregunta, quisimos analizar la influencia de la inmersión lingüística, particularmente en Canarias, sobre la adquisición de la lengua. En este caso hemos considerado el 


\section{GRÁFICO 12}

La pasiva refleja

\section{Se ....... muy pronto varios ejemplares gratuitos a todos los socios.*}

entregará

entrega

entregarán

$\checkmark$ ha entregado

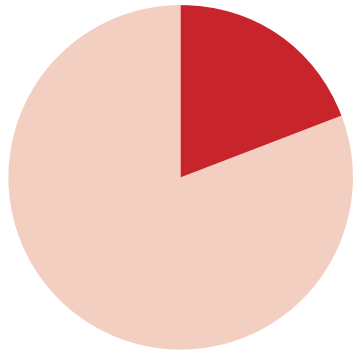

entregará: 19.23\% entregarán: 80.77\%

Fuente:

Elaboración propia

Ilamado fenómeno de pluralización indebida del verbo haber. Samper y Hernández (2012: 743) han definido este fenómeno como "la alternancia de las formas de singular y plural sin que de ello se deduzca un cambio de significación, ni semántica ni pragmática”. Según su estudio, este fenómeno se produce en muchas zonas de hispanohablantes, como en Venezuela, Chile, Puerto Rico y Canarias. Bentivoglio y Sedano (1989) han intentado dar una explicación a la utilización del plural de este verbo. Según ellas, la pluralización del verbo haber se debe a que este verbo tiene un solo argumento, permitiendo así considerar la frase nominal como sujeto y no como complemento directo. Dicho de otro modo, el verbo haber es impersonal, incompatible con el sujeto; al no haber un sujeto, se debería producir una conjugación en tercera persona del singular, pero el hablante otorga la función de sujeto al complemento directo que le sucede. Si el sustantivo con función de complemento directo está en plural, se produce el fenómeno de pluralización indebida del verbo haber. En su investigación, Samper y Hernández (2012) han descubierto que este fenómeno se da en todas las islas del archipiélago canario, tanto a nivel oral como escrito, en prensa y documentos oficiales, independientemente del nivel sociocultural de los hablantes.

Como podemos observar en el gráfico siguiente, un 67,31\% de los encuestados contestó de manera errónea. La causa más plausible de este error es la asimilación de la pluralización del verbo haber que caracteriza el fenómeno anteriormente nombrado. Esto viene a demostrar que el aprendizaje oral se traspasa al lenguaje escrito. Tal y como habíamos mencionado, la mayoría de los encuestados ha aprendido español de manera autónoma a través del contacto directo con la lengua. Por tanto, se ha producido una fosilización de un error a nivel regional que posteriormente ha sido asimilado por los aprendices rumanos de lengua castellana.

En cuanto al 5,77\% de los encuestados que escogieron la forma de pretérito imperfecto del verbo haber, existe la posibilidad de que asociaran una de las características de este tiempo verbal a la forma correcta; concretamente, la de expresar acciones repetitivas en el pasado y la aparición del adverbio de tiempo antes que suele acompañar al pretérito imperfecto.

En relación con el tiempo de inmersión en la lengua, la gran mayoría de los que han contestado de manera correcta llevan en España más de 10 años. 


\section{GRÁFICO 13}

Tiempos verbales. Conjugación del verbo haber indicativo, pretérito imperfecto

Echo de menos las cosas que ....... antes.*

habían

había

hubieran

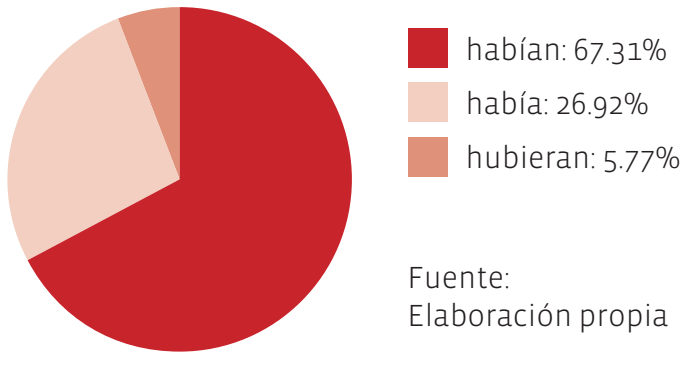

\subsubsection{El subjuntivo en la oración subordinada sustantiva}

La siguiente pregunta plantea una dificultad en cuanto a la elección entre el subjuntivo y el indicativo en una subordinada sustantiva con función de objeto directo. Esta parcela de la sintaxis del español es una de las más complejas, porque el modo se desenvuelve en un continuo que va desde un contexto en el que es necesario, obligado, como el indicativo, al otro extremo que es el subjuntivo, y en medio existen contextos que admiten la alternancia entre el indicativo y el subjuntivo. Los propios gramáticos del español no se aclaran acerca de dónde está la frontera. Existen ciertos criterios para distinguir su uso, aunque no hay delimitaciones exactas que rijan dónde comienza la obligatoriedad del indicativo o subjuntivo.

En el contexto planteado en la pregunta, el verbo esperar se recoge en la oración principal y tiene que ver con deseo o voluntad. Ese es uno de los factores que determina la presencia del subjuntivo. Como hemos visto en el marco teórico, en rumano el subjuntivo no existe. El modo más parecido al subjuntivo español es el conjunctiv, que puede expresar, a diferencia del modo español, una acción deseada, preferida, intencionada o no, demandada o recomendada. En la traducción de esta frase al rumano, el hablante utilizará para la frase subordinada el perfecto compuesto rumano, que tiene su equivalente en el pretérito perfecto simple del español o, lo que es lo mismo, utilizará la fórmula ha dado. Existe la posibilidad de que un hablante rumano haya realizado de manera consciente o inconsciente la transferencia de la lengua materna al español. Los resultados muestran que el 40,38\% ha elegido la forma de indicativo en lugar de la forma de subjuntivo. Al utilizar el indicativo, el hablante rumano está prescindiendo de esa característica propia del español; cuando el verbo de la principal indica un deseo, el verbo de la subordinada está en subjuntivo. El 5,77\% de los participantes utilizaron el condicional como modo en respuesta a la pregunta planteada. Según los estudios realizados por Fernández y Portillo (2000) y los de Hernández Alonso (1995: 176), existe una cierta tendencia entre los españoles a la uniformidad de tiempos verbales como son el subjuntivo y el condicional, por su proximidad en el sistema verbal y por la situación de contacto entre lenguas de distinta procedencia que facilitan la neutralización del rasgo de forma no actualizada del subjuntivo. Este fenómeno se puede observar mejor en la siguiente pregunta. 
Teniendo en cuenta las variables elegidas, hemos obtenido los siguientes resultados: un $61,72 \%$ de las respuestas acertadas pertenecen a rumanos que llevan más de 6 años en España, mientras el 38,28\% de los aciertos pertenece a rumanos que llevan menos de 5 años de residencia. Un 42,85\% de los participantes que contestaron de forma correcta afirma conocer más de un idioma a parte del rumano y el español.

\section{GRÁFICO 14}

El subjuntivo en la oración subordinada sustantiva

\section{Espero que te ...... tiempo de acabar.*}

ha dado

haya dado

habría dado

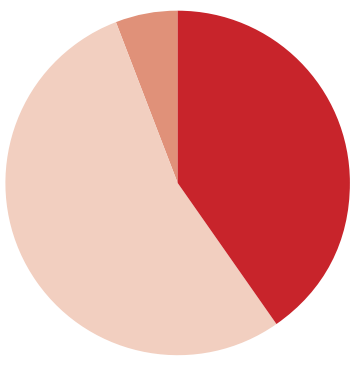

ha dado: $40.38 \%$ haya dado: $53.85 \%$ habría dado: $5.77 \%$

Fuente Elaboración propia

La segunda pregunta acerca del subjuntivo que hemos planteado es muy similar a la anterior. En este caso el valor de la oración principal es el de posibilidad, por tanto rige en la subordinada sustantiva el subjuntivo. Quisimos comprobar si los resultados se repiten en comparación con la pregunta anterior. Curiosamente, en este caso hay un mayor porcentaje de acierto. A la vez, ha crecido el número de hablantes rumanos que prefiere el uso del condicional en lugar del subjuntivo.

Una de las hipótesis para el incremento de las respuestas acertadas es el contexto del verbo en la oración principal. Mientras en el anterior se trataba de un deseo, en este es una posibilidad. Existe la eventualidad de que el hablante rumano haya considerado una mayor estabilidad en el verbo de probabilidad que en el de deseo. También habría que destacar que en la pregunta anterior se trataba del pretérito perfecto de subjuntivo, una forma verbal menos usual que la del presente. Un porcentaje relativamente alto, el 13,46\%, ha considerado oportuna la forma de indicativo presente, una de las formas que más se confunden con el subjuntivo. Curiosamente, un porcentaje aún más alto, 17,31\%, ha optado por el condicional. Esto puede darse por el contexto de probabilidad de la oración principal, ya que el condicional está estrechamente relacionado con situaciones potenciales. Por otra parte, habría que contemplar los estudios nombrados en la pregunta anterior, que revelan esa confusión que tienen los españoles entre el uso del condicional y el subjuntivo.

En cuanto a las variables, los resultados más destacables están en el tiempo de inmersión. El 42,85\% de las respuestas correctas las han proporcionado hablantes rumanos con menos de 5 años en España. A modo de resumen entre los resultados de ambas preguntas, existe la posibilidad de que los rumanos adquieran de manera más rápida el subjuntivo presente que el pretérito perfecto. 


\section{GRÁFICO 15}

El subjuntivo en la oración subordinada sustantiva

\section{Es posible que no ....... venir.*}

pueda

puedo

podría
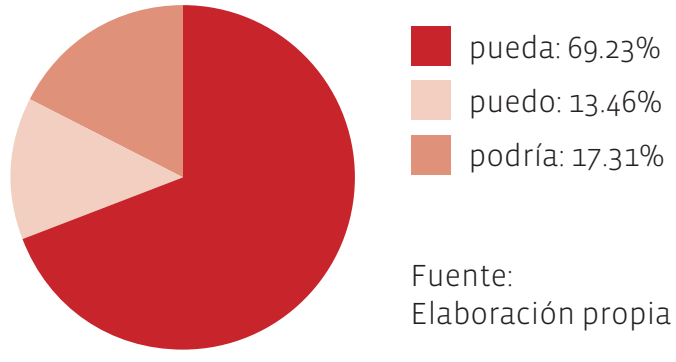

Elaboración propia

\subsubsection{El subjuntivo en la oración subordinada adjetiva}

Las subordinadas adjetivas o de relativo, tal y como las define Maneiro Vidal (2008: 53) son "oraciones compuestas que tienen como oración subordinada una cláusula que cumple las funciones de un sintagma adjetivo". Este tipo de oraciones están introducidas siempre por una partícula relativa; en nuestro caso, el pronombre relativo que.

En la gramática española, existen dos tipos de cláusulas: explicativas y especificativas. Las adjetivas explicativas, como indica el nombre, se unen al nombre para ofrecer información complementaria acerca de él. Son oraciones innecesarias que simplemente aclaran o amplifican una propiedad del nombre. El modo verbal que generalmente se emplea para este tipo de oraciones es el indicativo, aunque con algunas excepciones.

Las adjetivas especificativas, al contrario, son necesarias para comprender el significado del nombre. El modo verbal de estas subordinadas puede alternar entre el indicativo y el subjuntivo. Maneiro Vidal (2008: 56) nos aclara la diferencia entre los dos usos:

- Se utiliza el indicativo si el hablante hace referencia a personas, cosas o hechos concretos y específicos. El contenido de la cláusula es algo ya conocido.

- Se utiliza el subjuntivo cuando el hablante se refiere a personas hechos o cosas desconocidas o cuando el hablante no tiene la certeza de la realidad de su existencia. Cabe también la posibilidad de que el hablante tenga en mente a alguien o algo concreto pero no quiere o no puede identificarlo.

En nuestra pregunta, la elección entre indicativo y subjuntivo reside en la discrepancia de significado. Como hemos mencionado antes, el hablante rumano debe discernir si se trata de un objeto concreto, identificado, o de algo desconocido. Una de las pistas que hemos añadido a esta pregunta es la presencia del determinante indefinido algún, que acompaña al sustantivo coche y que no concreta su significado. Al tratarse de un objeto supuesto, del que no se tiene la certeza de que exista, la oración subordinada adjetiva rige el subjuntivo. 
Según los resultados que hemos hallado, un 73,08\% de los participantes ha contestado correctamente. Tal y como hemos visto en el estudio sociológico, la mayor parte de los rumanos ha aprendido el español por su propia cuenta, en entornos comunicativos o de manera autodidacta, por ende, es de suponer que han adquirido la forma sin saber las reglas gramaticales que rigen su uso. Del porcentaje de respuestas incorrectas, el 19,23\% ha escogido el verbo en indicativo y el 7,69\% el condicional. En rumano, al igual que en español, la oración subordinada adjetiva se puede introducir mediante los pronombres relativos. El problema está en que la forma del modo conjunctiv que se emplearía en este caso es la misma que la del presente indicativo más la partícula să. Al traducirla, el hablante rumano tiende a utilizar el indicativo. Tal y como explican Madrona y Pisot (2009) en este tipo de oraciones, el hablante rumano opta por utilizar el indicativo, pero en situaciones ideales con antecedente desconocido prefiere la estructura del subjuntivo (introducida por care să):

Busco un chico que sea fiel. - Caut un băiat care să fie fidel.

Posiblemente, se haya producido una transferencia del rumano al español a causa de este hecho. Por otra parte, el uso del condicional en esta frase puede deberse a un error en la extracción del significado. Es posible que el hablante rumano haya confundido la probabilidad del contexto con la condición de su existencia.

Incluyendo las variables en el análisis, los resultados muestran que un 37,83\% de las respuestas correctas pertenece a rumanos con menos de 5 años en España. Más aún, del total de respuestas correctas, el 43,24\% afirma conocer dos idiomas o más.

\section{GRÁFICO 16}

El subjuntivo en la oración subordinada adjetiva

¿Tiene algún coche que no ...... demasiado?*

cueste

cuesta

costara

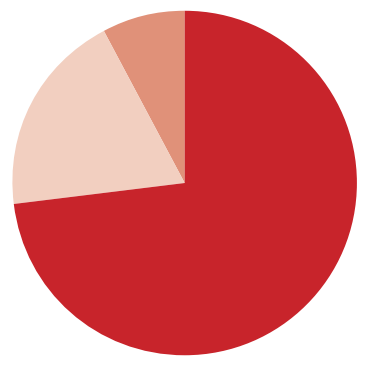

cueste: $73.08 \%$ cuesta: $19.23 \%$ costara: $7.69 \%$

Fuente: Elaboración propia

\subsubsection{El dígrafo $r r$}

En español el dígrafo $r$ - o sucesión de dos erres simples - se corresponde siempre con un sonido único: el vibrante fuerte [rr]. El sonido vibrante múltiple [rr] puede aparecer grafiado como r o con el dígrafo rr. Según la RAE (2000), si la letra r aparece en posición inicial de palabra o precedida de las consonantes $n$, I o s, representa el sonido apicoaveolar vibrante múlti- 
ple [rr]. El dígrafo rr se emplea para representar el sonido vibrante múltiple /rr/ en posición intervocálica.

En rumano, el sonido [rr] es una consonante líquida vibrante, según la Academia Romana (2012), y corresponde a un sonido que se produce a través de la vibración del ápice de la lengua y los alvéolos. Su sonido es muy parecido a la vibrante simple española aunque con menos fuerza. En cuanto a la grafía, el dígrafo rr no existe en rumano.

En la siguiente pregunta, quisimos saber si los hablantes rumanos eran capaces de diferenciar entre la consonante r simple y el dígrafo rr, utilizando para ello dos conjugaciones del verbo querer. La particularidad de este verbo es que su futuro y condicional del modo indicativo cambian la grafía a rr. Por tanto, se trata de una doble intencionalidad en la pregunta. A través de la identificación del tiempo verbal, el hablante rumano sería capaz de conocer su grafía. Para lograrlo, hemos comenzado la frase con un adverbio de tiempo, ayer, que localiza la acción en el pasado. Según los resultados, un 61,54\% de los participantes contestó de manera correcta, utilizando el pretérito imperfecto del verbo querer. El 32,69\% de los restantes eligió la forma del condicional. Esto puede ser causado por dos razones: primero, por un error de transferencia entre el sonido [rr] del español y el rumano; al ser vibrante, el hablante rumano pudo haber relacionado la grafía con el sonido, y, segundo, por un desconocimiento del empleo del condicional en español. Finalmente, un 5,77\% ha elegido como variante correcta la forma del pretérito imperfecto del subjuntivo. No existe ninguna hipótesis válida para esta elección, ya que no se trata de ninguna acción probable, sino declarada.

Con respecto a otros idiomas, en francés el dígrafo rr no existe, al igual que en rumano. En cambio, en inglés sí existe, aunque el sonido se corresponde con la vibrante simple alveolar española [r] en reducidos casos. De las respuestas correctas, la mayoría pertenecen a hablantes con más de 10 años en España. Se trata de un resultado significativo que indica que la adquisición del dígrafo rr podría ser más tardía.

En la pregunta número tres, habíamos planteado una situación similar, en la que el sonido [rr] aparece en posición intervocálica, en la palabra aburrida. Los resultados mostraron que un 7,69\% de los encuestados realizó de manera correcta la concordancia entre adjetivo y sustantivo, pero desconoce las reglas de ortografía con respecto al dígrafo rr (véase el gráfico 17).

\section{Conclusiones}

Una dificultad principal que recoge la literatura acerca de las dificultades de los hablantes rumanos de español como lengua extranjera reside en la concordancia. Martí Puig y Moliner García (2003) y Roesler (2011) destacaban las dificultades de concordancia de género entre artículo y nombre. En la comparación que habíamos realizado entre el rumano y el español, 


\section{GRÁFICO 17}

El dígrafo $r$ r

\section{Ayer no ...... ir al fútbol.*}

querría

quería

quisiera

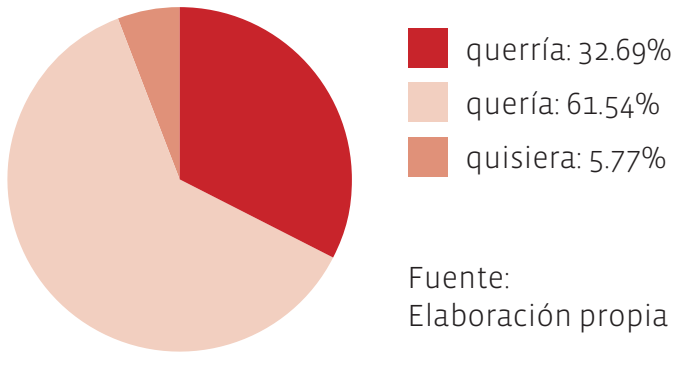

destacábamos el estudio realizado por Chireac, Serrat y Huguet (2011) acerca de la flexión nominal en rumano. A diferencia del español, el rumano tiene tres géneros: masculino, femenino y neutro, cada uno con una flexión nominal propia. Según sus investigaciones, las mayores dificultades que presentan los rumanos residen en la discriminación de género y número entre los determinantes o artículos que suelen acompañar a los nombres y estos. En nuestra investigación, hemos querido comprobar si estas dificultades a nivel oral también se dan a nivel escrito. Los resultados muestran que un tercio de los entrevistados tiene dificultades para realizar la concordancia entre el artículo indeterminado y el sustantivo. Como mencionábamos antes, en rumano el artículo se aglutina al sustantivo o adjetivo a manera de sufijo. En el caso de los sustantivos articulados femeninos en singular la terminación se realiza en la vocal a, herencia del latín. La confusión ocurre cuando el hablante rumano se encuentra con sustantivos de género masculino en español acabados en a. El hablante, al detectar la desinencia de femenino de su lengua materna realiza la concordancia, tanto en los determinantes como en los artículos, en femenino. Estos resultados confirman la tesis de Roesler (2007) que afirma que la mayoría de las particularidades que se dan en el español hablado por rumanos corresponde al resultado de la transferencia de la lengua materna.

Asimismo, hemos querido comprobar si los hablantes rumanos realizan correctamente la concordancia entre el sustantivo y el adjetivo. En los estudios analizados en el marco teórico, esta concordancia no se definía como una de las dificultades del lenguaje oral. Nuestros resultados recogen que el $11,5 \%$ de los participantes no realiza de manera correcta la concordancia entre sustantivo y adjetivo. Se trata de un resultado significativo que merece ser estudiado en mayor profundidad. La única referencia acerca del adjetivo la encontramos en el estudio comparativo realizado por Tamas (2005), en el que se destaca la utilización de la partícula del comparativo y superlativo mai como interferencia positiva en la adquisición del español. Al igual que en el caso anterior, los errores de concordancia entre el sustantivo y el adjetivo se deben a la atribución de los sustantivos de género masculino en español a los de femenino, por influencias de la lengua materna. Se trata de unos errores de interferencia lingüística negativa, en los que la estructura de la lengua materna es una barrera en el proceso de aprendizaje de una lengua extranjera. 
En lo que se refiere a la concordancia entre los determinantes indefinidos y los sustantivos, en cuanto a número, nuestros resultados muestran que el 17,3\% de los encuestados no la realiza de manera correcta. Hemos considerado como causa de este error dos hipótesis plausibles: la primera puede ser una confusión en la función morfológica del determinante; si el hablante le atribuye la función de adverbio, es probable que conscientemente no realice la concordancia. La segunda puede ser a causa del español hablado en Canarias, que tiende a prescindir de la pronunciación de la s en posición final. Para esta última hipótesis habría que añadir que la mayoría de los rumanos encuestados han afirmado haber aprendido el idioma de manera oral. Acerca de los errores de concordancia entre los determinantes indefinidos y los sustantivos, Serramitja (2009: 821) afirma que estos se producen por las declinaciones nominales con paradigmas muy marcados en rumano, que distinguen género, número y caso.

Según afirman Martí Puig y Moliner García (2003), una de las principales dificultades que tienen los rumanos en español es la conjugación de los verbos. En nuestra investigación, hemos querido comprobar cuáles son los tiempos y modos verbales que más dificultades generan. Hemos observado que el presente del modo indicativo no presenta ninguna dificultad para los participantes de la encuesta. Posteriormente, hemos planteado una pregunta acerca de la utilización del verbo haber como auxiliar en la formación del pretérito perfecto compuesto. Los resultados mostraron que más de un cuarto de los encuestados no supieron emplear de manera correcta la forma del auxiliar. Tal y como afirmaba Chireac (2012), consideramos que este error se debe a que en la lengua rumana no existe una diferencia entre los pretéritos indefinido y perfecto del indicativo; se utiliza solo un tiempo verbal para expresar el pasado, el perfecto compuesto, que a diferencia del español se refiere a una acción finalizada en el momento del habla.

De igual modo, hemos planteado a los participantes una oración de pasiva refleja. Los resultados mostraron que existe cierta dificultad para diferenciar entre la pasiva refleja y la oración impersonal. En rumano, la pasiva refleja se extiende a todas las personas. La marca de pasiva refleja se en rumano se utiliza tanto para la tercera persona del singular como del plural. Al tratarse de un pronombre que introduce tanto el singular como el plural, el hablante rumano puede optar por elegir bien la forma verbal de singular o bien la de plural, sin tener en cuenta el sujeto de la frase. Los errores cometidos pueden ser por una transferencia del rumano al español con respecto a las oraciones impersonales o por confundir las funciones sintácticas del complemento directo y el sujeto.

Las conclusiones más Ilamativas de este estudio residen en la pregunta planteada acerca del uso del verbo haber en pretérito imperfecto del indicativo en la oración subordinada atributiva. Los resultados mostraron que el 73,08\% de los encuestados había contestado de manera errónea. Teniendo en cuenta los estudios realizados por Samper y Hernández (2012), los errores cometidos por los hablantes rumanos pueden ser el resultado del llamado fenómeno de pluralización indebida del verbo haber. Bentivoglio y Sedano (1989) afirman que la 
pluralización del verbo haber se debe a que este verbo tiene un solo argumento, permitiendo así considerar la frase nominal como sujeto y no como complemento directo. Dicho de otro modo, el verbo haber es impersonal, incompatible con el sujeto; al no haber un sujeto, se debería producir una conjugación en tercera persona del singular, pero el hablante otorga la función de sujeto al complemento directo que le sucede. Si el sustantivo con función de complemento directo está en plural, se produce el fenómeno de pluralización indebida del verbo haber. Esta característica es propia del español hablado en Canarias y en otros países de América Latina. A través de estos resultados, se demuestra que el aprendizaje oral de la lengua se ve reflejado en las producciones escritas.

Otro de los modos verbales considerados como problemáticos para el hablante rumano es el subjuntivo. En la lengua rumana, por influencia griega, el subjuntivo se emplea en situaciones distintas a las que se usa en español (Chireac, 2010). El modo subjuntivo, Ilamado conjunctiv en rumano, presenta formas de presente y perfecto, las dos acompañadas de la partícula invariable să. Al igual que en español, expresa una acción posible, deseable o dudosa, aunque también posee formas verbales declarativas. Generalmente las construcciones del conjunctiv comienzan con formas del verbo poder, querer y tener que o necesitar. En su estructura de presente el primer verbo se conjuga según la persona, pero el segundo verbo no queda en infinitivo, como en español, sino que también se conjuga. Las preguntas que hemos propuesto presentan el subjuntivo en dos variantes distintas: en la oración subordinada sustantiva y en la oración subordinada adjetiva. Según los resultados, las mayores dificultades se encuentran en las subordinadas sustantivas. Los hablantes rumanos eligen sustituir el subjuntivo por el indicativo o por el condicional. Este error se produce por la interferencia de la lengua materna, ya que en rumano el modo conjunctiv emplea el mismo tiempo verbal para las dos formas verbales presentes en la oración. En cuanto a la preferencia por el condicional, el mayor porcentaje de error se sitúa en las oraciones que expresan probabilidad. Entre los hablantes de español existe cierta tendencia a asimilar el subjuntivo con el condicional por la proximidad en el sistema verbal (Hernández Alonso, 1995: 176; Fernández y Portillo, 2000).

Asimismo, hemos decidido plantear un problema ortográfico relacionado con el dígrafo rr, utilizando para ello una particularidad del verbo querer: que su futuro y condicional del modo indicativo cambian la grafía a rr. Los resultados mostraron que más de un tercio de los hablantes rumanos confunde la grafía del pretérito imperfecto del verbo querer con la del condicional. Consideramos que la principal causa de este error reside en la interferencia negativa del sonido [rr], que en rumano se representa con una sola ere aunque se trata de una consonante líquida vibrante.

Finalmente, hemos incluido en nuestro análisis de los resultados dos variables que consideramos como relevantes para dar respuesta a los errores encontrados. Por una parte, hemos querido saber si el conocimiento de otros idiomas influye en la adquisición del español 
como segunda, tercera o cuarta lengua. Los resultados mostraron que en algunas situaciones gramaticales aquellos participantes que afirmaron conocer el francés y el inglés tuvieron más aciertos que los que solamente conocían el rumano. En ciertos casos hemos observado como la interferencia con el español puede producirse desde otros idiomas. Por otra parte, hemos querido saber si el periodo de inmersión lingüística era determinante en la elección de las respuestas. Paradójicamente, a nivel de concordancia, de pasiva refleja y en algún caso de subjuntivo existe mayor porcentaje de error entre los que más tiempo llevan en inmersión. Este resultado indica que se ha producido una fosilización de los errores por falta de un aprendizaje formal.

El trabajo de investigación que hemos desarrollado pretende ofrecer una visión muy reducida del área de dificultades de los rumanos en el español escrito. Para este estudio, hemos seleccionado solamente una parte de la dificultades del lenguaje oral y hemos incluido algunos aspectos que consideramos como problemáticos. Esta investigación puede considerarse como punto de partida de futuros trabajos relacionados con la enseñanza del español, no solamente a la comunidad rumana, sino también a todos aquellos colectivos cuya lengua de proveniencia sea una lengua romance. Alentamos a los investigadores a que sigan indagando en las dificultades del lenguaje escrito en español, para así poder ofrecer las herramientas necesarias a los docentes de español como lengua extranjera.

\section{Bibliografía citada}

Academia Romana, 2012: DEX-Dictionarul explicativ al limbii romane, București: Univers Enciclopedic Gold.

Amérigo Cuervo-Arango, María, 1993: "Metodología de cuestionarios: principios y aplicaciones", Boletín de la ANABAD 43 (3-4), 263-272.

Bentivoglio, Paola, y Mercedes Sedano, 1989: "Haber: ¿un verbo impersonal? Un estudio sobre el español de Caracas”, Estudios sobre español de América y lingüística afroamericana, Bogotá: Instituto Caro y Cuervo, 59-81.

Bisquerra Alzina, Rafael, 1989: Métodos de investigación educativa. Guía práctica, Barcelona: CEAC, 236.

ChIREAc, Silvia Maria, 2012: La adquisición del catalán y del castellano por los escolares inmigrantes de origen rumano y chino. Un análisis sistemático de los usos correctos y erróneos en la expresión oral, Cluj Napoca: Presa Universitara Clujeana.

Chireac, Silvia-María, Elisabet Serrat y Ángel Huguet, 2011: "Transferencia en la adquisición de segundas lenguas. Un estudio con alumnado rumano en un contexto bilingüe", Revista de Psicodidáctica 16 (2), 267-289. 
CiRSteA, Marcela-Aniela, 2006: "Análisis contrastivo de errores en el aprendizaje del español como lengua extranjera", Language and Literature. European Landmarks of Identity 2, Editura Universitatii Pitești, 268- 271.

CorbetTA, Piergiorgio, 2003: Metodología y técnicas de investigación social, Madrid: McGraw-Hill.

EBEL, Robert L., 1979: Essentials of Educational Measurement, tercera edición, Prentice Hall, 116.

Fernández Ulloa, Teresa, y Rosario Portillo Mayorga, 2000: "Uso del imperfecto y pluscuamperfecto de subjuntivo entre estudiantes universitarios de Bilbao (País Vasco) y Santander (Cantabria)", Onomázein 5, 167-187.

García Beltrán, Ángel, y otros, 2006: "La autoevaluación como actividad docente en entornos virtuales de aprendizaje/enseñanza”, RED. Revista de Educación a Distancia M6, 1-14.

GonzÁlez Faraco, Juan Carlos, y otros, 2011: "Representaciones e imágenes de la diversidad cultural: reflexiones a partir de un estudio exploratorio con profesores de escuelas multiculturales del suroeste de Andalucía”, Profesorado. Revista de Currículum y Formación de Profesorado 15 (3), 181-194.

Gràcia, Lluïsa, 2007: “Diversidad Tipológica Y Adquisición De Segundas Lenguas I: Flexión Verbal Y Orden Sintáctico”, Revista Española de Lingüística (RSEL) 37, 7-40.

Hernández Alonso, César, 1995: Nueva sintaxis de la lengua española, Salamanca: Ediciones Colegio de España, 176.

Instituto Nacional de Estadística (INE), 2016: Población extranjera por nacionalidad y sexo [www. ine.es, fecha de consulta: 15 de febrero de 2016].

Iorgu, Iordan, 1965: "Paralelos lingüísticos rumano-españoles” en Actas del II Congreso de la Asociación Internacional de Hispanistas, Nimega: Universidad de Radboud, 347-355.

IORGU, Iordan, 1968: "Observaciones sobre la formación de palabras en español” en Actas del III Congreso de la Asociación Internacional de Hispanistas, México: Universidad de México, 443-452.

Krashen, Stephen, 1982: Principles and practice in second language acquisition, University of Southern California, 7-14.

Latorre, Antonio, Delio del Rincón y Justo Arnal, 1996: "Bases metodológicas de la investigación educativa”, Capítulo 7. Metodología no experimental, Barcelona: GRg2, 173-196.

LeubA, Richard J., 1986: "Machine-Scored Testing, Part I: Purposes, Principles, and Practices", Engineering Education 77 (2), 89-95.

Madrona Fernández, Alberto, y Rafael Pisot Díaz, 2009: Diferencias de usos gramaticales entre el español y el rumano, Madrid: EDINUMEN, 29-144. 
ManeIRo Vidal, Manuel, 2008: Gramática práctica del español actual. Tercer curso, Carolina del Norte: Editorial Lulu.com, 53-56.

Martí Puig, Manuel, y Odet Moliner García, 2003: "Español para inmigrantes rumanos adultos" en Actas del XIII Congreso de ASELE: El español, lengua del mestizaje y la interculturalidad, Universidad de Madrid, 577-585.

Núñez Villuendas, Adoración, 2005: "Incidencias de la entrevista personal en la investigación mediante encuesta”, Revista Española de Investigaciones Sociológicas 109, 219-236.

O'Nions, Helen, 2010: "Different and unequal: the educational segregation of Roma pupils in Europe", Intercultural Education 21, 1-13.

Real Academia Española, 2000: Ortografía de la lengua española, Madrid: Espasa.

Real Academia Española, 2010. Nueva gramática de la lengua española. Manual, Madrid: Espasa.

RoEsLer, Patrick, 2007: “La integración lingüística de inmigrantes rumanos en Alicante”, RedELERevista Electrónica de Didáctica/Español Lengua Extranjera 11, 1-19.

RoesLer, Patrick, 2011: "Características generales del español hablado por inmigrantes rumanos en Castellón de la Plana”, RedELE-Revista Electrónica de Didáctica/Español Lengua Extranjera 22, 1-23.

Samper Padilla, José Antonio, y Clara Eugenia Hernández Cabrera, 2012: "En torno a los usos personales de haber en el español de Las Palmas de Gran Canaria", Cum corde et in nova grammatica, Servizo de Publicacións e Intercambio Científico da Universidade de Santiago de Compostela $927,743-754$.

Selinker, Larry, 1972: "Interlanguage”, IRAL X (2), 209-231.

SerRamitja, Julià Laia, 2009: La adquisición de los determinantes del español por parte de hablantes chinos, rusos y rumanos: Codificación de los errores. Tesis doctoral, Universitat de Girona, 819-826.

TAmas, Elisabeta Silvia, 2005: "Análisis cuantitativo y cualitativo del nivel del español en Rumanía”, comunicación presentada en el XL Congreso 400 años de Don Quijote: pasado y perspectivas de futuro, Asociación Europea de Profesores de Español, Valladolid, 306-317.

Uță Burcea, Ofelia Mariana, 2010: "El Rumano escrito de España. Un Análisis de Habla”, Philologica Jassyensia VI 1 (11), 237-254. 